\title{
Is Prophylactic Hyperthermic Intraperitoneal Chemotherapy Beneficial to The Long-Term Survival of Patients After Radical Gastric Cancer Surgery: A Systematic Review and Meta-analysis
}

\author{
Xuhui Zhuang \\ The First Affiliated Hospital of Guangzhou University of Chinese Medicine \\ Yuewen He \\ The First Affiliated Hospital of Guangzhou University of Chinese Medicine \\ Wuhua Ma ( $\square$ tuesdaymorninggz@126.com ) \\ The First Affiliated Hospital of Guangzhou University of Chinese Medicine
}

Research Article

Keywords: Gastric cancer, Peritoneal cancer, Hyperthermic intraperitoneal chemotherapy, HIPEC, Meta-analysis.

Posted Date: October 13th, 2021

DOI: https://doi.org/10.21203/rs.3.rs-871449/v1

License: (1) This work is licensed under a Creative Commons Attribution 4.0 International License. Read Full License 


\section{Abstract}

Background: Hyperthermic intraperitoneal chemotherapy (HIPEC) has been proven to improve the survival rate of gastric cancer and reduce peritoneal recurrence. We aimed to evaluate the effectiveness and safety of prophylactic HIPEC after radical gastric cancer surgery in this study.

Methods: Researchers searched for studies published in PubMed, Embase, Web of science, Scopus, Cochrane, Clinicalkey databases and Microsoft Academic databases to identify studies that examine the impact of prophylactic HIPEC on the survival, recurrence and adverse events of patients undergoing radical gastric cancer surgery. RevMan 5.3 was used to analyze the results and risk of bias. The PROSERO registration number is CRD42021262016.

Results: This meta-analysis included 19 studies with a total of 2097 patients, 12 of which are RCTs. The results showed that the 1-,3-and 5-year overall survival rate was significantly favorable to HIPEC (OR=5.10,2.47,1.96 respectively). Compared with the control group, the overall recurrence rate and peritoneal recurrence rate of the HIPEC group were significantly lower (OR=0.43,0.26 respectively). Significantly favorable to the control group in terms of renal dysfunction and pulmonary dysfunction complications( $\mathrm{OR}=2.44,6.03$ respectively). Regarding the causes of death due to postoperative recurrence: liver recurrence, lymph node and local recurrence and peritoneal recurrence, the overall effect is not significantly different (OR=0.81,1.19,0.37 respectively).

Conclusions: 1-,3-and 5-year overall survival follow-up can be incremented by the prophylactic HIPEC, and which can significantly reduce the overall recurrence rate and peritoneal recurrence rate. HIPEC can cause significant pulmonary dysfunction and renal dysfunction complications. No difference has been found in the deaths due to recurrence after surgery.

\section{Introduction}

Gastric cancer (GC) is not only one of the most common malignant tumors in the world, but also the malignant tumor with the second highest mortality rate among all kinds of tumors ${ }^{[1,2]}$. More than $70 \%$ of GC occur in developing countries, and more than $50 \%$ of cases occur in East Asia ${ }^{[3]}$. $\mathrm{Liu}^{[4]}$ et al. pointed out in a study published in 2020 that China's annual morbidity and mortality of GC are twice the world average. At present, surgical resection is the only possible cure for gastric cancer ${ }^{[5]}$, however, the 5 -year survival rate is still not satisfactory. Recurrence after GC treatment surgery is quite common, about $10 \%-46 \%$ will have peritoneal recurrence after surgery ${ }^{[6,7]}$. Peritoneal dissemination is one of the main reasons for gastric cancer recurrence and metastasis in the abdominal cavity. And it will cause peritoneal cancer (PC), which is more complicated and harder to treat than GC.

Although some scholars have proposed in recent years that adjuvant chemotherapy and neoadjuvant chemotherapy can slightly improve the survival rate after radical gastric cancer surgery $[7,8]$, they have not shown to significantly reduce the distant metastasis rate. Despite the use of systemic chemotherapy and other methods, the survival rate of patients with advanced GC is still not ideal. It may be due to the existence of the "plasmaperitoneal barrier" $[9,10]$ that can isolate the abdominal cavity from the effect of intravenous chemotherapy, which leads to the poor response of PC and advanced GC to systemic chemotherapy. Some evidence in the peritoneal dialysis literature indicates that the peritoneal permeability of some hydrophilic anticancer drugs may be much lower than the plasma clearance rate. Pharmacokinetic calculations indicate that the concentration of this intraperitoneal ingested drug is expected to be much higher in the abdominal space than in the plasma ${ }^{[11]}$. At the same time, hyperthermia has been developed as an anti-cancer therapy. It is one of the most widely studied chemotherapy and radiotherapy sensitizers ${ }^{[12,13]}$, and it has been proven that it has a direct cytotoxic effect on tumor cells in the abdominal cavity in combination with certain anti-cancer chemotherapy. Therefore, a new combination therapy has been introduced in recent years, namely hyperthermic intraperitoneal perfusion chemotherapy (HIPEC), which is considered to be an effective method to control the peritoneal dissemination of GC patients after the radical GC surgery $[2,14,15]$. Since HIPEC has been proven effective for PC, peritoneal pseudomyxoma and other diseases, it has been included in the national treatment standards of some EU countries. But the safety and effectiveness of prophylactic HIPEC in patients with advanced gastric cancer and patients after radical gastric cancer surgery is still a hot topic of debates.

Can prophylactic HIPEC really improve the long-term survival rate of patients with radical GC? Effectively control peritoneal transmission? These are still the questions we want to explore. Therefore, this systematic review and meta-analysis will use the results of RCTs and high-quality NRCTs to comprehensively evaluate the effectiveness and safety of prophylactic HIPEC for patients after radical GC surgery in terms of short-term or long-term survival rate (1-,3- and 5-years), recurrence rate, complications and deaths due to recurrence after surgery.

\section{Methods}

\section{Search strategy}

This review was conducted in accordance with the Preferred Reporting Items for Systematic Reviews and meta-analyses (PRISMA) guidelines, and we completed the PRISMA checklist according to the guidelines. Two investigators (X.H.Z, Y.W.H) searched for studies published in PubMed, Embase, Web of science, Scopus, Cochrane, and Clinicalkey databases from the inception to June 12, 2021. In addition, X.H.Z searched Microsoft Academic, and all search results are listed in PRISMA_2020_flow_diagram (Fig. 1). The researcher sets the search conditions as topic keywords and abstracts. There are no language restrictions throughout the search process. The search terms are: (HIPEC OR CHPP OR chemotherapeutic hyperthermic intraperitoneal 
perfusion OR intraperitoneal hyperthermic perfusion chemotherapy OR Peritoneal thermal perfusion OR Hyperthermic intraperitoneal perfusion OR IHPC OR CCCHP OR Coelom Continued Circulatory Hyperthermia Perfusion OR intraperitoneal chemohyperthermia) AND (gastric carcinoma OR gastric cancer OR stomach cancer OR Carcinoma of stomach OR radical gastrectomy for cancer OR Laparoscopic radical gastrectomy OR radical gastrectomy OR Radical operation of gastric carcinoma OR radical extremital partial gastrectomy OR radical operation for carcinoma of stomach OR radical correction for stomach cancer). We will change the search formula for different databases. In order to avoid omissions, we choose the search formula with the most search results.

\section{Study Selection}

The study selection process is carried out in EndNote X9 (Thomson Reuters, NY, USA). The entire retrieval process is divided into three parts. First, X.H.Z saves the respective search results of the two investigators to EndNote X9 and finds duplicates. After deleting all duplicate studies, X.H.Z will exclude studies marked as ineligible by automation tools or other reasons that cannot enter the second stage of screening. Subsequently, we screened out clinical studies and excluded Meta-analysis, Case reports, Reviews, Animal experiments, Letter, Laboratory studies, Guidelines, and conference abstract. The second stage is to screen the studies based on the topic, abstract and keywords. In this process, we use the Rating in EndNote $\mathrm{X} 9$ to rank the research. Two investigators marked the studies with "low relevance" as "one star", "medium credibility" as "2-3 stars", and "high credibility" as "4-5 star". "The stars" determines the subsequent screening process. "One-star" research will be excluded at this stage, the "2-3 stars" needs to be reevaluated by all investigators (X.H.Z Y.W.H W.H.M), and the "4-5 stars" can be included in the full text review. The third stage is the full-text review of the included studies. Two researchers excluded the studies of different from inclusion criteria, fail to obtain and protocol. We use Modified methodological index for non-randomized studies (MINORS) score[16, 17] to evaluate the quality of non-randomized control trails (NRCTs) and exclude studies with a total score of <12. All disputes during the Study Selection process are resolved by the third investigator (W.H.M).

\section{Eligibility Criteria}

The purpose of this review is to evaluate the role of prophylactic HIPEC after radical resection of gastric cancer. Therefore, the inclusion criteria of the study are as follows: gastric cancer patients undergoing radical surgery, postoperative prophylactic HIPEC, blank control group or concurrent postoperative chemotherapy. And we excluded gastric cancer palliative surgical treatment, without peritoneal metastases, historical control, nonpostoperative HIPEC, IPEC and non-chemotherapeutic intraperitoneal perfusion. Due to the small number of RCTs, we included some NRCTs and conducted quality assessments.

\section{Risk of Bias Assessment}

Two reviewers (X.H.Z, Y.W.H) used RevMan 5.3 (Review Manager. Version 5.3. Copenhagen: The Nordic Cochrane Centre, The Cochrane Collaboration, 2014.) to assess the risk of bias in RCTs. The authors' review of each risk of bias item's judgment is presented as a percentage of all included studies in Fig. 2. The authors' judgment of the risk of bias items for each of the included studies is shown in Fig. 3. The evaluation results are expressed as low risk, high risk and unclear. In case of dispute, W.H.M will determine the evaluation result.

\section{Data Extraction}

Two investigators (X.H.Z, Y.W.H) completed the data extraction independently, and W.H.M was responsible for handling different points of view. According to the Modified methodological index for non-randomized studies (MINORS) score, we will analyze the data included in the NRCT and complete the quality assessment Table 1 . In addition, we extracted the characteristics of the studies and patients and summarized them in Table 2. The contents are as follows: Author, year of publication, Country, RCT/NRCT, Study period, matched factors, and the stage of stomach cancer. The characteristics of the interventions will be summarized in Table 3. 
Table 1

Modified MINORS score of all eligible NRCT.

\begin{tabular}{|c|c|c|c|c|c|c|c|c|c|c|}
\hline Author & Year & $\begin{array}{l}\text { Consecutive } \\
\text { patients }\end{array}$ & $\begin{array}{l}\text { Prospective } \\
\text { data collection }\end{array}$ & $\begin{array}{l}\text { Reported } \\
\text { endpoints }\end{array}$ & $\begin{array}{l}\text { Unbiased } \\
\text { outcome } \\
\text { evaluation }\end{array}$ & $\begin{array}{l}\text { Appropriate } \\
\text { controls }\end{array}$ & $\begin{array}{l}\text { Contemporary } \\
\text { groups }\end{array}$ & $\begin{array}{l}\text { Groups } \\
\text { equivalent }\end{array}$ & $\begin{array}{l}\text { Sample } \\
\text { size }\end{array}$ & Score \\
\hline Liu & 2020 & 2 & 1 & 2 & 1 & 2 & 2 & 0 & 2 & 12 \\
\hline Xie & 2020 & 2 & 1 & 2 & 1 & 2 & 2 & 1 & 2 & 13 \\
\hline Rosa & 2021 & 1 & 1 & 2 & 2 & 2 & 2 & 1 & 1 & 12 \\
\hline Zhu & 2020 & 1 & 1 & 2 & 2 & 2 & 2 & 2 & 1 & 13 \\
\hline Diniz & 2020 & 2 & 2 & 2 & 2 & 2 & 2 & 1 & 1 & 14 \\
\hline Zhong & 2020 & 2 & 1 & 2 & 2 & 2 & 2 & 2 & 2 & 15 \\
\hline Zhang & 2020 & 1 & 1 & 2 & 1 & 1 & 2 & 1 & 2 & 11 \\
\hline Yonemura & 1995 & 2 & 1 & 2 & 1 & 2 & 2 & 1 & 2 & 13 \\
\hline Hall & 2004 & 1 & 1 & 1 & 1 & 2 & 2 & 1 & 2 & 11 \\
\hline Gao & 2016 & 2 & 1 & 1 & 1 & 2 & 2 & 1 & 1 & 11 \\
\hline Kunisaki & 2002 & 2 & 2 & 2 & 2 & 2 & 1 & 1 & 2 & 14 \\
\hline Kang & 2013 & 2 & 1 & 2 & 2 & 2 & 2 & 2 & 1 & 14 \\
\hline Yarema & 2014 & 2 & 1 & 2 & 2 & 2 & 2 & 1 & 1 & 13 \\
\hline Akiyama & 2002 & 0 & 0 & 1 & 1 & 1 & 1 & 1 & 2 & 7 \\
\hline Kobayashi & 1998 & 0 & 0 & 0 & 2 & 0 & 1 & 1 & 2 & 6 \\
\hline \multicolumn{11}{|c|}{ MINORS: methodological index for non-randomised studies. } \\
\hline \multicolumn{11}{|c|}{ NRCT: Non-Randomized Controlled Trial } \\
\hline Only studie & ith sc & es> 12 can b & cluded in the $\mathrm{n}$ & a-analysis. & & & & & & \\
\hline
\end{tabular}


Table 2

Summary of the 22 eligible studies

\begin{tabular}{|c|c|c|c|c|c|c|c|c|c|c|}
\hline Author Yr & Country & RCT/NRCT & HIPEC & Control & $\begin{array}{l}\text { Study } \\
\text { period }\end{array}$ & $\begin{array}{l}\text { Matched } \\
\text { factors }\end{array}$ & $\begin{array}{l}\text { State } \\
\mathrm{I} / \mathrm{II}\end{array}$ & III & IV & TNM \\
\hline Liu 2020 & China & NRCT & 64 & 64 & $\begin{array}{l}\text { January } 2010 \text { to April } \\
2012\end{array}$ & 1246 & 0 & 128 & 0 & ND \\
\hline Cui 2014 & China & RCT & 48 & 48 & $\begin{array}{l}\text { January } 2006 \text { to } \\
\text { January } 2010\end{array}$ & 12346 & 0 & 96 & 0 & ND \\
\hline $\begin{array}{l}\text { Fujimura } \\
1994\end{array}$ & Japan & RCT & 22 & 18 & $\begin{array}{l}\text { March } 1988 \text { to March } \\
1992\end{array}$ & 123456 & 13 & 14 & 13 & $\mathrm{~T}_{2-4} \mathrm{~N}_{0-2} \mathrm{M}_{0}$ \\
\hline Fan 2021 & China & RCT & 33 & 17 & $\begin{array}{l}\text { March } 2015 \text { to } \\
\text { November } 2016\end{array}$ & 1246 & ND & ND & ND & $\mathrm{T}_{1-4} \mathrm{~N}_{0-3} \mathrm{M}_{0}$ \\
\hline $\begin{array}{l}\text { Hamazoe } \\
1994\end{array}$ & Japan & RCT & 42 & 40 & $\begin{array}{l}\text { January } 1983 \text { to October } \\
1986\end{array}$ & 12346 & 14 & 57 & 11 & ND \\
\hline Xie 2020 & China & NRCT & 51 & 62 & ND & 12346 & ND & ND & ND & $\mathrm{T}_{4} \mathrm{~N}_{0-3} \mathrm{M}_{0}$ \\
\hline $\begin{array}{l}\text { Reutovich } \\
2019\end{array}$ & Belarus & RCT & 68 & 55 & 2008 to 2016 & 12346 & 0 & 133 & 0 & $\mathrm{~T} 4_{\mathrm{a}-\mathrm{b}} \mathrm{N}_{0-3} \mathrm{M} 0$ \\
\hline Koga 1988 & Japan & RCT & 26 & 21 & $\begin{array}{l}\text { July } 1980 \text { to February } \\
1983\end{array}$ & 1246 & 2 & 39 & 6 & ND \\
\hline Rosa 2021 & Italy & NRCT & 23 & 39 & $\begin{array}{l}\text { January } 2006 \text { to } \\
\text { December } 2015\end{array}$ & 1245 & 7 & 45 & 10 & ND \\
\hline Zhu 2020 & China & NRCT & 22 & 21 & $\begin{array}{l}\text { Jul 1, } 2018 \text { to Dec 31, } \\
2019\end{array}$ & 124 & 9 & 34 & 0 & ND \\
\hline Diniz 2020 & Brazil & NRCT & 28 & 56 & 2006 to 2017 & 12456 & 39 & 45 & 0 & ND \\
\hline Zhong 2020 & China & NRCT & 61 & 68 & January 2016 to & 12346 & 54 & 75 & 0 & ND \\
\hline & & & & & June 2017 & & & & & \\
\hline $\begin{array}{l}\text { Yonemura } \\
1995\end{array}$ & Japan & NRCT & 79 & 81 & 1984 to 1992 & 12345 & 44 & 49 & 67 & ND \\
\hline $\begin{array}{l}\text { Fujimoto } \\
1999\end{array}$ & Japan & RCT & 71 & 70 & $\begin{array}{l}\text { March } 1987 \text { to } \\
\text { December } 1996\end{array}$ & 1245 & ND & ND & ND & $\mathrm{T}_{2-4} \mathrm{~N}_{1-2} \mathrm{M}_{0}$ \\
\hline Kim 2001 & Korea & RCT & 52 & 51 & 1990 to 1995 & 1246 & 17 & 48 & 38 & $\mathrm{~T}_{3-4} \mathrm{~N}_{0-3} \mathrm{M}_{0-1}$ \\
\hline Hirose 1999 & Japan & RCT & 15 & 40 & $\begin{array}{l}\text { October } 1988 \text { to October } \\
1995\end{array}$ & 123456 & 14 & 31 & 10 & ND \\
\hline $\begin{array}{l}\text { Ikeguchi } \\
1995\end{array}$ & Japan & RCT & 78 & 96 & 1980 to 1989 & 123456 & ND & ND & ND & $\mathrm{T}_{2-4} \mathrm{~N}_{0-2} \mathrm{M}_{0-1}$ \\
\hline $\begin{array}{l}\text { Takahashi } \\
1995\end{array}$ & Japan & RCT & 56 & 57 & $\begin{array}{l}\text { January } 1987 \text { to } \\
\text { December } 1992\end{array}$ & 12346 & 13 & 54 & 46 & ND \\
\hline $\begin{array}{l}\text { Beeharry } \\
2019\end{array}$ & China & RCT & 40 & 40 & $\begin{array}{l}\text { December } 2014 \text { to June } \\
2015\end{array}$ & 12346 & 11 & 69 & 0 & ND \\
\hline $\begin{array}{l}\text { Kunisaki } \\
2002\end{array}$ & Japan & NRCT & 45 & 79 & $\begin{array}{l}\text { April } 1992 \text { to March } \\
1999\end{array}$ & 123456 & 28 & 55 & 41 & ND \\
\hline Kang 2013 & $\begin{array}{l}\text { Taiwan, } \\
\text { ROC. }\end{array}$ & NRCT & 29 & 83 & $\begin{array}{l}\text { January } 2002 \text { to } \\
\text { December } 2010\end{array}$ & 12346 & ND & ND & ND & $\mathrm{T}_{2-4} \mathrm{~N}_{0-3} \mathrm{M}_{0-1}$ \\
\hline Yarema 2014 & Ukraine & NRCT & 19 & 19 & 2008 to 2012 & 12345 & 19 & 19 & 0 & ND \\
\hline \multicolumn{11}{|c|}{ HIPEC: hyperthermic intraperitoneal chemotherapy; } \\
\hline \multicolumn{11}{|c|}{ RCT: randomized control trial; } \\
\hline \multicolumn{11}{|c|}{ NRCT: Non-Randomized Controlled Trial; } \\
\hline \multicolumn{11}{|c|}{ ND: not declared; } \\
\hline \multicolumn{11}{|l|}{ Yr: year; } \\
\hline
\end{tabular}




\begin{tabular}{|c|c|c|c|}
\hline Author Yr & Surgery & HIPEC group & Control group \\
\hline Liu 2020 & Radical gastrectomy & $\begin{array}{l}\text { Surgery+ HIPEC+ systemic chemotherapy } \\
\text { HIPEC: Oxaliplatin }\left(100 \mathrm{mg} / \mathrm{m}^{2}\right) \text { and } 0.9 \% \text { sodium chloride } \\
\text { solution }(3000 \mathrm{~mL}) \text { at } 1,4 \text { days; fluorouracil }(0.75 \mathrm{~g}) \text { and } 0.9 \% \\
\text { sodium chloride solution }(3000 \mathrm{~mL}) \text { at } 2,3 \mathrm{days} \\
\text { Dexamethasone }(10 \mathrm{mg}) \text { and } 2 \% \text { lidocaine }(10 \mathrm{~mL}) 1-4 \text { days. } \\
\text { Time: postoperative } 1 \text { to } 2 \text { days (once a day, lasting } 90 \\
\text { min each time), last for } 4 \text { days } \\
\text { Temperature: } 42-44^{\circ} \mathrm{C}\end{array}$ & $\begin{array}{l}\text { Surgery+ systemic } \\
\text { chemotherapy } \\
\text { Chemotherapy: paclitaxel } 135 \\
\mathrm{mg} / \mathrm{m}^{2}(1 \mathrm{~d}), \text { cisplatin } 20 \\
\mathrm{mg} / \mathrm{m}^{2} \text { and tegafur } 1.0 \mathrm{~g} \mathrm{(1-} \\
5 \mathrm{~d}), 4 \text { weeks } 6 \text { cycles } \\
\text { Time: } 2 \text { weeks postoperative }\end{array}$ \\
\hline Cui 2014 & $\begin{array}{l}\text { Radical resection of the gastric } \\
\text { cancer }\end{array}$ & $\begin{array}{l}\text { Surgery+ HIPEC+ systemic chemotherapy } \\
\text { HIPEC: Cisplatin }\left(60 \mathrm{mg} / \mathrm{m}^{2}\right) \text { and } 0.9 \% \text { sodium chloride } \\
\text { solution }(3000 \mathrm{~mL}) \text { at } 1,4 \text { days; fluorouracil }(0.75 \mathrm{~g}) \text { and } 0.9 \% \\
\text { sodium chloride solution }(3000 \mathrm{~mL}) \text { at } 2,3 \text { days; } \\
\text { Dexamethasone }(10 \mathrm{mg}) \text { and } 2 \% \text { lidocaine }(10 \mathrm{~mL}) 1-4 \text { days. } \\
\text { Time: postoperative } 1 \text { to } 2 \text { days (once a day, lasting } 90 \\
\text { min each time), last for } 4 \text { days } \\
\text { Temperature: } 41-43^{\circ} \mathrm{C}\end{array}$ & $\begin{array}{l}\text { Surgery+ systemic } \\
\text { chemotherapy }\end{array}$ \\
\hline $\begin{array}{l}\text { Fujimura } \\
1994\end{array}$ & $\begin{array}{l}\text { Curative } \\
\text { resection }\end{array}$ & $\begin{array}{l}\text { Surgery+ HIPEC } \\
\text { HIPEC: MMC }(30 \mathrm{mg}) \text { and cisplatinum }(300 \mathrm{mg}) \text { in } 10 \text { liters } \\
\text { saline solution } \\
\text { Time: } 60 \mathrm{~min} \\
\text { Temperature: } 41-42^{\circ} \mathrm{C}\end{array}$ & Surgery \\
\hline Fan 2021 & Radical gastrectomy & $\begin{array}{l}\text { Surgery+ HIPEC+ chemotherapy with SOX regime } \\
\text { HIPEC: Cisplatin }(50 \mathrm{mg} / \mathrm{L}) \text { and } 0.9 \% \text { sodium chloride solution } \\
\text { Time: } 30 \mathrm{~min} \\
\text { Temperature: } 42.5-43^{\circ} \mathrm{C}\end{array}$ & $\begin{array}{l}\text { Surgery+ chemotherapy with } \\
\text { soX regime }\end{array}$ \\
\hline $\begin{array}{l}\text { Hamazoe } \\
1994\end{array}$ & Radical gastrectomy & $\begin{array}{l}\text { Surgery+ HIPEC } \\
\text { HIPEC: } M M C(10 \mu \mathrm{g} / \mathrm{ml}) \text { in } 0.9 \% \text { saline solution. } \\
\text { Time: } 50-60 \mathrm{~min} \\
\text { Temperature: } 44-45^{\circ} \mathrm{C}\end{array}$ & Surgery \\
\hline Xie 2020 & $\begin{array}{l}\text { laparoscopic-assisted radical } \\
\text { gastrectomy }\end{array}$ & $\begin{array}{l}\text { Surgery+ HIPEC+ systemic chemotherapy (SELOX or SOX) } \\
\text { HIPEC: Cisplatin }(50 \mathrm{mg} / \mathrm{L}) \text { and } 0.9 \% \text { sodium chloride solution } \\
\text { Time: } 60 \mathrm{~min} \\
\text { Temperature: } 42-43^{\circ} \mathrm{C}\end{array}$ & $\begin{array}{l}\text { Surgery + systemic } \\
\text { chemotherapy (SELOX or SOX) }\end{array}$ \\
\hline $\begin{array}{l}\text { Reutovich } \\
2019\end{array}$ & $\begin{array}{l}\text { total or partial (distal subtotal } \\
\text { resection) gastrectomy with } \\
\text { free margins (R0 resection) } \\
\text { and D2 lymph node dissection }\end{array}$ & $\begin{array}{l}\text { Surgery+ HIPEC } \\
\text { HIPEC: Ringer's solution }(5-6 \mathrm{~L}) \text {, cisplatin }\left(50 \mathrm{mg} / \mathrm{m}^{2}\right) \text { and } \\
\text { doxorubicin }\left(50 \mathrm{mg} / \mathrm{m}^{2}\right) \\
\text { Temperature: } 42^{\circ} \mathrm{C}\end{array}$ & Surgery \\
\hline
\end{tabular}

HIPEC: hyperthermic intraperitoneal chemotherapy;

Yr: year;

MMC: mitomycin C;

CRS: Cytoreductive Surgery;

Matching: 1, age; 2 , gender; 3 , histology; 4, stage; 5 , lymphadenectomy; 6 , type of gastrectomy. 


\begin{tabular}{|c|c|c|c|}
\hline Author $\mathrm{Yr}$ & Surgery & HIPEC group & Control group \\
\hline \multirow{4}{*}{$\begin{array}{l}\text { Koga } \\
1988\end{array}$} & \multirow[t]{4}{*}{ Curative surgery } & Surgery+ HIPEC & \multirow[t]{4}{*}{ Surgery } \\
\hline & & HIPEC: MMC (8-10 mg/L) in $2000 \mathrm{ml}$ saline solution & \\
\hline & & Time: 50-60min & \\
\hline & & Temperature: $44-45^{\circ} \mathrm{C}$ & \\
\hline \multirow{4}{*}{$\begin{array}{l}\text { Rosa } \\
2021\end{array}$} & \multirow[t]{4}{*}{ Gastrectomy } & Surgery+ HIPEC & \multirow[t]{4}{*}{ Surgery } \\
\hline & & $\begin{array}{l}\text { HIPEC: Cisplatin }\left(75 \mathrm{mg} / \mathrm{m}^{2}\right), \mathrm{MMC}\left(15 \mathrm{mg} / \mathrm{m}^{2}\right) \text {, and } 0.9 \% \\
\text { sodium chloride solution }\left(2 \mathrm{~L} / \mathrm{m}^{2}\right)\end{array}$ & \\
\hline & & Time: 90min & \\
\hline & & Temperature: $41-42^{\circ} \mathrm{C}$ & \\
\hline \multirow[t]{4}{*}{ Zhu 2020} & \multirow[t]{4}{*}{ Gastrectomy } & Surgery+ HIPEC+ chemotherapy & \multirow[t]{4}{*}{ Surgery+ chemotherapy } \\
\hline & & $\begin{array}{l}\text { HIPEC: Cisplatin }\left(75 \mathrm{mg} / \mathrm{m}^{2}\right) \text { and } 2000 \mathrm{ml} 0.9 \% \text { sodium chloride } \\
\text { solution }\end{array}$ & \\
\hline & & Time: 60min & \\
\hline & & Temperature: $41.5-42.5^{\circ} \mathrm{C}$ & \\
\hline \multirow[t]{4}{*}{$\begin{array}{l}\text { Diniz } \\
2020\end{array}$} & \multirow[t]{4}{*}{ Curative resection } & Perioperative chemotherapy + surgery + HIPEC & \multirow[t]{4}{*}{$\begin{array}{l}\text { Perioperative chemotherapy + } \\
\text { surgery }\end{array}$} \\
\hline & & HIPEC: MMC $\left(38 \mathrm{mg} / \mathrm{m}^{2}\right)$ in saline solution & \\
\hline & & Time: 90min & \\
\hline & & Temperature: $41-42^{\circ} \mathrm{C}$ & \\
\hline \multirow{4}{*}{$\begin{array}{l}\text { Zhong } \\
2020\end{array}$} & Laparoscopic-assisted & Surgery + HIPEC & \multirow[t]{4}{*}{ Surgery } \\
\hline & \multirow[t]{3}{*}{ radical gastrectomy } & $\begin{array}{l}\text { HIPEC: Lobaplatin }\left(50 \mathrm{mg} / \mathrm{m}^{2}\right) \text { and } 3000 \mathrm{~mL} 5 \% \text { intravenous } \\
\text { glucose solution. }\end{array}$ & \\
\hline & & Time: 60min & \\
\hline & & Temperature: $43^{\circ} \mathrm{C}$ & \\
\hline \multirow{4}{*}{$\begin{array}{l}\text { Yonemura } \\
1995\end{array}$} & \multirow[t]{4}{*}{ Gastrectomy } & Surgery+ HIPEC & \multirow[t]{4}{*}{ Surgery } \\
\hline & & $\begin{array}{l}\text { HIPEC: Cisplatin ( } 300 \mathrm{mg}), \mathrm{MMC}(30 \mathrm{mg}) \text {, and } 0.9 \% \text { sodium } \\
\text { chloride solution }(8 \mathrm{~L})\end{array}$ & \\
\hline & & Time: 60min & \\
\hline & & Temperature: $41.5-43.5^{\circ} \mathrm{C}$ & \\
\hline
\end{tabular}

HIPEC: hyperthermic intraperitoneal chemotherapy;

Yr: year;

MMC: mitomycin C;

CRS: Cytoreductive Surgery;

Matching: 1 , age; 2 , gender; 3 , histology; 4, stage; 5 , lymphadenectomy; 6 , type of gastrectomy.

Page $7 / 22$ 


\begin{tabular}{|c|c|c|c|}
\hline Author $\mathrm{Yr}$ & Surgery & HIPEC group & Control group \\
\hline \multirow{4}{*}{$\begin{array}{l}\text { Fujimoto } \\
1999\end{array}$} & \multirow[t]{4}{*}{ Gastrectomy } & Surgery+ HIPEC & \multirow[t]{4}{*}{ Surgery } \\
\hline & & $\begin{array}{l}\text { HIPEC: } \mathrm{MMC}(10 \mathrm{mg} / \mathrm{ml}) \text {, and } 0.9 \% \text { sodium chloride solution (3- } \\
\text { (4) }\end{array}$ & \\
\hline & & Time: $120 \mathrm{~min}$ & \\
\hline & & Temperature: $44.5-45^{\circ} \mathrm{C}$ & \\
\hline \multirow[t]{4}{*}{ Kim 2001} & \multirow[t]{4}{*}{ Subtotal or total gastrectomy } & Surgery+ HIPEC & \multirow[t]{4}{*}{ Surgery } \\
\hline & & HIPEC: MMC (40 mg), and dialysis solution (4000cc) & \\
\hline & & Time: $120 \mathrm{~min}$ & \\
\hline & & Temperature: $44.5-45.7^{\circ} \mathrm{C}$ & \\
\hline \multirow{3}{*}{$\begin{array}{l}\text { Hirose } \\
1999\end{array}$} & \multirow[t]{3}{*}{ Gastrectomy } & Surgery+ HIPEC & \multirow[t]{3}{*}{ Surgery } \\
\hline & & HIPEC: cisplatin (100mg), MMC (20mg) and etoposide (100mg) & \\
\hline & & Temperature: $41-44.5^{\circ} \mathrm{C}$ & \\
\hline \multirow{4}{*}{$\begin{array}{l}\text { Ikeguchi } \\
1995\end{array}$} & \multirow[t]{4}{*}{ Curative resection } & Surgery+ HIPEC & \multirow[t]{4}{*}{ Surgery } \\
\hline & & HIPEC: MMC $\left(80-100 \mathrm{mg} / \mathrm{m}^{2}\right), 8-10 \mathrm{~L}$. & \\
\hline & & Time: 50-60min & \\
\hline & & Temperature: $44-45^{\circ} \mathrm{C}$ & \\
\hline \multirow{2}{*}{$\begin{array}{l}\text { Takahashi } \\
1995\end{array}$} & \multirow[t]{2}{*}{ Gastrectomy } & Surgery+ HIPEC & \multirow[t]{2}{*}{ Surgery } \\
\hline & & $\begin{array}{l}\text { HIPEC: MMC ( } 50 \mathrm{mg}) \text {, Activated carbon }(375 \mathrm{mg}) \text {, Saline } \\
(100 \mathrm{ml}) \text {. }\end{array}$ & \\
\hline \multirow{4}{*}{$\begin{array}{l}\text { Beeharry } \\
2019\end{array}$} & \multirow[t]{4}{*}{ Gastrectomy } & Surgery+ HIPEC & \multirow[t]{4}{*}{ Surgery } \\
\hline & & HIPEC: cisplatin (50mg/L) & \\
\hline & & Time: 60min & \\
\hline & & Temperature: $41-43^{\circ} \mathrm{C}$ & \\
\hline \multirow{4}{*}{$\begin{array}{l}\text { Kunisaki } \\
2002\end{array}$} & \multirow[t]{4}{*}{ Gastrectomy } & Surgery+ HIPEC & \multirow[t]{4}{*}{ Surgery } \\
\hline & & $\begin{array}{l}\text { HIPEC: Cisplatin }(150 \mathrm{mg}), \mathrm{MMC}(15 \mathrm{mg}) \text {, and etoposide } \\
(150 \mathrm{mg}) \text { in } 5 \text { to } 6 \mathrm{~L} \text { physiologic saline }\end{array}$ & \\
\hline & & Time: 40min & \\
\hline & & Temperature: $42-43^{\circ} \mathrm{C}$ & \\
\hline
\end{tabular}

HIPEC: hyperthermic intraperitoneal chemotherapy;

Yr: year;

MMC: mitomycin C;

CRS: Cytoreductive Surgery;

Matching: 1 , age; 2 , gender; 3 , histology; 4, stage; 5 , lymphadenectomy; 6 , type of gastrectomy. 


\begin{tabular}{|c|c|c|c|}
\hline Author Yr & Surgery & HIPEC group & Control group \\
\hline \multirow{5}{*}{$\begin{array}{l}\text { Kang } \\
2013\end{array}$} & \multirow[t]{5}{*}{ Gastrectomy } & Surgery+ HIPEC & \multirow[t]{5}{*}{ Surgery } \\
\hline & & HIPEC: cisplatin (30 mg/L), MMC (10 mg/L), and & \\
\hline & & etoposide $(20 \mathrm{mg} / \mathrm{L})$ in $3-4 \mathrm{~L}$ of lactated Ringer solution & \\
\hline & & Time: $60 \mathrm{~min}$ & \\
\hline & & Temperature: $41-43^{\circ} \mathrm{C}$ & \\
\hline \multirow{4}{*}{$\begin{array}{l}\text { Yarema } \\
2014\end{array}$} & \multirow[t]{4}{*}{ Gastrectomy } & Surgery+ HIPEC & \multirow[t]{4}{*}{ Surgery } \\
\hline & & HIPEC: MMC $\left(12.5 \mathrm{mg} / \mathrm{m}^{2}\right)$, cisplatin $\left(75 \mathrm{mg} / \mathrm{m}^{2}\right)$ & \\
\hline & & Time: 90min & \\
\hline & & Temperature: $41-43.6^{\circ} \mathrm{C}$ & \\
\hline \multicolumn{4}{|c|}{ HIPEC: hyperthermic intraperitoneal chemotherapy; } \\
\hline \multicolumn{4}{|l|}{ Yr: year; } \\
\hline \multicolumn{4}{|c|}{ MMC: mitomycin C; } \\
\hline \multicolumn{4}{|c|}{ CRS: Cytoreductive Surgery; } \\
\hline \multicolumn{4}{|c|}{ Matching: 1 , age; 2 , gender; 3 , histology; 4 , stage; 5 , lymphadenectomy; 6 , type of gastrectomy. } \\
\hline
\end{tabular}

\section{Outcomes}

The primary outcome of this review is the overall survival at 3 years follow-up. The secondary outcomes are the overall survival at 1-and 5-years follow-up; recurrence rate: overall and peritoneal; complication: myelosuppression, leakage, intestinal obstruction, liver dysfunction; deaths due to recurrence after surgery: liver, lymph node and local and peritoneal recurrence.

\section{Statistical Analysis}

All the data that needs to be analyzed are dichotomous data, and we choose to report odds ratio (OR). RevMan 5.3 also reported the heterogeneity of the data while producing the forest plot. For heterogeneity test $P<0.05$ or $\mathrm{I}_{2}>50 \%$, we choose random effects model. When the heterogeneity test $P>0.05$ or $\mathrm{I}_{2}<50 \%$, the fixed effects model is often selected. Subgroup analysis is based on the overall heterogeneity inspection results. The fixed effects model is used when the results of heterogeneity between subgroups are consistent, and the random effects model is used when the results of heterogeneity are inconsistent. If the heterogeneity test result $\left.\right|^{2}>80 \%$, we need to perform a sensitivity analysis on the data to exclude studies with significant heterogeneity.

\section{Results}

\section{Literature Search Findings}

Two researchers (X.H.Z Y.W.H) searched PubMed, Embase, Web of science, Scopus, Cochrane, Clinicalkey, and Microsoft Academic databases, and a total of 2533 studies were obtained. X.H.Z used EndNote X9 to remove 1268 duplicate studies. We excluded 12 records marked as ineligible by automation tools and 2 studies due to incomplete information. And two investigators independently reviewed the initially included studies and excluded 542 non-clinical studies (Review: 349; Meta-analysis: 26; Case report: 42; Letter: 28; Animal experiments: 26; Laboratory studies: 26; Guidelines or Conference Abstract: 45). Based on the number of "stars" marked in EndNote X9, we screened clinical studies in the second stage, and 126 studies can be reviewed in full text. After excluding 99 studies, 27 included articles were identified. We evaluated the quality of NRCT among them, three studies with a score of $<12$ were excluded[18-22]. This review finally included 22 articles. The literature search findings are represented in PRISMA_2020_flow_diagram (Fig. 1).

\section{Study and Patient Characteristics}

The characteristics of the included studies are summarized in Table 2. A total of 19 studies (RCT:12 NRCT:10) with 2097 patients were included in this review. Among them, 9 studies were published after 2015. Most of the included studies are from Asia, including 8 from mainland China[23-29] and Taiwan ROC[30], 10 from Japan[31-39] and Korea[40]. The other three studies are from Belarus[41], Italy[42], Ukraine[43], and Brazil[44]. Matched factors mainly include the following: age, gender, histology, stage, lymphadenectomy, type of gastrectomy. If the above content is reported in the research, the investigators will use the corresponding number of the representative to express it. The included studies all reported the patient's age, gender, and stage of gastric cancer. For the staging of gastric cancer, 8 studies[25, 27, 30, 34, 35, 37, 40, 41] reported the TMN staging situation, and 15 studies[23, 24, 26, 28, 29, 31-33, 36, 38-40, 42-44] listed the number of patients in each stage. The studies of Liu[26] et al., Cui[28] et al., and Reutovich[41] et al. included only stage III patients. 


\section{Intervention characteristics}

Two investigators summarized the intervention characteristics of the included studies in Table 3. In the included studies, the choice of chemotherapeutics for HIPEC was mainly MMC or Cisplatin or a combination of the two. The HIPEC protocol chosen by cui and his colleagues[28] is as follows: Cisplatin $\left(60 \mathrm{mg} / \mathrm{m}^{2}\right)$ and $0.9 \%$ sodium chloride solution $(3000 \mathrm{~mL})$ at 1,4 days; fluorouracil $(0.75 \mathrm{~g})$ and $0.9 \%$ sodium chloride solution $(3000 \mathrm{~mL})$ at 2 ,3days; Dexamethasone (10 mg) and 2\% lidocaine (10 mL) 1-4days; temperature: $41-43^{\circ} \mathrm{C}$. Xie[25] et al. used Cisplatin (50 mg/L) and $0.9 \%$ sodium chloride solution for $60 \mathrm{~min}$, temperature: $42-43^{\circ} \mathrm{C}$. Reutovich[41] et al. chose Ringer's solution (5-6L), cisplatin (50 mg/m²) and doxorubicin $\left(50 \mathrm{mg} / \mathrm{m}^{2}\right)$, Temperature: $42^{\circ} \mathrm{C}$. Zhu[23] et al.'s solution is: Cisplatin $\left(75 \mathrm{mg} / \mathrm{m}^{2}\right)$ and $2000 \mathrm{ml} 0.9 \%$ sodium chloride solution for $60 \mathrm{~min}$, temperature: $41.5-42.5^{\circ} \mathrm{C}$. Beeharry[29] et al. and his colleagues used cisplatin ( $\left.50 \mathrm{mg} / \mathrm{L}\right)$ for $60 \mathrm{~min}$, temperature: $41-43^{\circ} \mathrm{C}$. The researchers used $\mathrm{MMC}$ chemotherapy in 8 studies. The method of Hamazoe[33] et al. is: $\mathrm{MMC}(10 \mu \mathrm{g} / \mathrm{ml})$ in $0.9 \%$ saline solution for $50-60 \mathrm{~min}$, temperature: $44-45^{\circ} \mathrm{C}$. Koga[32] et al. chose MMC (8-10 mg/L) in $2000 \mathrm{ml}$ saline solution for $50-60 \mathrm{~min}$, temperature: $44-45^{\circ} \mathrm{C}$. Diniz[44] et al. used $\mathrm{MMC}\left(38 \mathrm{mg} / \mathrm{m}^{2}\right)$ in saline solution for Time: $90 \mathrm{~min}$, temperature: $41-42^{\circ} \mathrm{C}$. Fujimoto and his colleagues[35] chose MMC (10 mg/ml), and $0.9 \%$ sodium chloride solution (3-4L) for $120 \mathrm{~min}$, temperature: $44.5-45^{\circ} \mathrm{C}$. Kim[40] et al. chose MMC (40 mg) and dialysis solution (4000 cc) for 60 min, temperature: $44.5-45.7^{\circ} \mathrm{C}$ in RCT. Ikeguchi[37] et al. chose MMC (80-100 mg/ $\mathrm{m}^{2}$ ) for 50-60 min, temperature: $44-45^{\circ} \mathrm{C}$. Takahashi[38] et al method is: MMC (50 mg), Activated carbon (375mg), Saline (100ml). In addition, 7 studies chose the HIPEC scheme of MMC+ cisplatin. Fujimura[34] et al. used MMC (30 mg) and cisplatinum (300 mg) in 10 liters saline solution for $60 \mathrm{~min}$, temperature: $41-42^{\circ} \mathrm{C}$. Rosa[42] et al. used Cisplatin $\left(75 \mathrm{mg} / \mathrm{m}^{2}\right)$, MMC $\left(15 \mathrm{mg} / \mathrm{m}^{2}\right)$, and $0.9 \%$ sodium chloride solution $\left(2 \mathrm{~L} / \mathrm{m}^{2}\right)$ for $90 \mathrm{~min}$, temperature: $41-42^{\circ} \mathrm{C}$. Yonemura[31] et al. and his colleagues used Cisplatin (300mg), MMC (30mg), and $0.9 \% \mathrm{sodium}$ chloride solution (8L) for $60 \mathrm{~min}$, temperature: $41.5-43.5^{\circ} \mathrm{C}$. Hirose[36] et al. reported cisplatin (100mg), MMC (20mg) and etoposide (100mg), temperature: $41-44.5^{\circ} \mathrm{C}$. Kunisaki[39] et al. chose cisplatin (150mg), MMC (15mg), and etoposide $(150 \mathrm{mg})$ in 5 to $6 \mathrm{~L}$ physiologic saline for $40 \mathrm{~min}$, temperature: $42-$ $43^{\circ} \mathrm{C}$. Kang[30] et al. chose cisplatin $(30 \mathrm{mg} / \mathrm{L}), \mathrm{MMC}(10 \mathrm{mg} / \mathrm{L})$, and etoposide $(20 \mathrm{mg} / \mathrm{L})$ in $3-4 \mathrm{~L}$ of lactated Ringer solution for $60 \mathrm{~min}$, temperature: 41-43 ${ }^{\circ} \mathrm{C}$. Yarema[43] et al. used MMC $(12.5 \mathrm{mg} / \mathrm{m} 2)$, cisplatin $(75 \mathrm{mg} / \mathrm{m} 2)$ for $90 \mathrm{~min}$, temperature: $41-43.6^{\circ} \mathrm{C}$. In addition, the study by Liu[26] et al. used Oxaliplatin $\left(100 \mathrm{mg} / \mathrm{m}^{2}\right)$ and $0.9 \%$ sodium chloride solution $(3000 \mathrm{~mL})$ at 1,4 days; fluorouracil $(0.75 \mathrm{~g})$ and $0.9 \%$ sodium chloride solution (3000 $\mathrm{mL})$ at 2 ,3days; Dexamethasone (10 mg) and $2 \%$ lidocaine (10 mL) 1-4days, temperature: $42-44^{\circ} \mathrm{C}$. Zhong[24] et al. used Lobaplatin (50 mg/m ${ }^{2}$ ) and $3000 \mathrm{~mL} 5 \%$ intravenous glucose solution for $60 \mathrm{~min}$, Temperature: $43^{\circ} \mathrm{C}$.

\section{Risk of Bias Assessment and Study Quality}

Two investigators used RevMan 5.3 to assess the risk of bias for 12 RCTs. The evaluation result is shown in Fig. 2, Fig. 3. Among all the included RCTs, 3 studies[27, 29, 38] reported the method of random sequence generation, Beeharry[29] et al. and Takahashi[38] et al. reported on the concealment of random sequences. Hirose[36] et al. and Kim[40] et al. pointed out in the study that random sampling cannot be achieved due to the particularity of interventions. Although we evaluate this as high risk, this cannot be the basis for excluding these two studies. Only Beeharry et al. reported blinding the researchers responsible for data statistics, and none of the other studies mentioned blinding. In addition, the simple size is small in two studies[32, 36], and there may be a risk of reporting bias.

\section{Meta-analysis and Synthesis Overall 1-year survival (Fig. 4.1A)}

Four studies (2RCTs, 3NRCTs), 415 patients were reported overall 1-year survival[25, 26, 28, 34, 43]. Analyzing under the random effects model, the overall heterogeneity $\left(\mathrm{I}_{2}=62 \%\right)$ is acceptable. The Overall 1 -year survival rate was significantly favorable to the $\mathrm{HIPEC}(\mathrm{OR}=5.10,95 \% \mathrm{Cl}=1.41-18.45)$.

\section{Overall 3-year survival (Fig. 4.1B)}

Ten studies (7RCTs, 4NRCTs), 1049 patients were reported overall 3-year survival[24-28, 32, 34, 36, 38, 39, 41]. Analyzing under the random effects model, the overall heterogeneity $\left(\mathrm{I}_{2}=57 \%\right)$ is acceptable. The Overall 3 -year survival rate was significantly favorable to the $\mathrm{HIPEC}(\mathrm{OR}=2.47,95 \% \mathrm{Cl}=$ 1.58-3.85).

\section{Overall 5-year survival (Fig. 4.2)}

Seven studies (4RCTs, 5NRCTs), 997 patients were reported overall 5-year survival[26, 30, 31, 33, 36, 37, 39, 40, 42]. Analyzing under the random effects model, the overall heterogeneity $\left(\mathrm{I}_{2}=56 \%\right)$ is acceptable. The Overall 5-year survival rate was significantly favorable to the HIPEC (OR=1.96, $95 \% \mathrm{Cl}=1.27-3.04)$.

\section{Overall 3-year survival in different HIPEC ways (Fig. 5)}

Eight studies (3Cisplatin, 2MMC, 3Cisplatin + MMC), 696 patients were reported overall 3-year survival in different HIPEC ways. Analyzing under the random effects model, the overall heterogeneity $\left(\mathrm{I}_{2}=64 \%\right)$ is acceptable. The overall 3-year survival in different HIPEC ways was significantly favorable to the HIPEC $(\mathrm{OR}=2.41,95 \% \mathrm{Cl}=1.32-4.40)$.

\section{Overall recurrence rate (Fig. 6A)}


Seven studies, 807 patients were reported overall recurrence rate[23, 25, 26, 28, 36, 40, 44]. Using random effects model analysis, the heterogeneity is significant. Therefore, we conducted a sensitivity analysis and finally excluded studies[44] that caused significant heterogeneity. Six studies with 538 patients were evaluated. Using fixed effects model analysis, the heterogeneity is no longer significant $\left(\mathrm{I}_{2}=27 \%\right)$. The overall recurrence rate was significantly favorable to the HIPEC (OR=0.43, 95\% Cl = 0.29-0.65).

\section{Peritoneal recurrence rate (Fig. 6B)}

Eleven studies, 1119 patients were reported peritoneal recurrence rate[23-25, 29, 36, 37, 39, 40, 42, 43]. Using random effects model analysis, the heterogeneity is significant. The previous sensitivity analysis has excluded study with significant heterogeneity[44]. Using random effects model analysis, the heterogeneity is no longer significant $\left(\mathrm{I}_{2}=53 \%\right)$. The peritoneal recurrence rate was significantly favorable to the $\mathrm{HIPEC}(\mathrm{OR}=0.26,95 \% \mathrm{Cl}=$ 0.15-0.48).

Complication: myelosuppression (Fig. 7A).

In six studies, 646 patients reported the incidence of postoperative myelosuppression[25, 28, 29, 35, 38, 40]. Analyzing under the fixed effects model, the overall heterogeneity $\left(\mathrm{I}_{2}=0 \%\right)$ is not significant. The overall effect is not significantly different $(\mathrm{OR}=1.37,95 \% \mathrm{Cl}=0.77-2.42)$.

Complication: leakage (Fig. 7B).

In twelve studies, 1107 patients reported the incidence of postoperative leakage[24, 25, 27, 29, 32, 33, 35, 36, 38-40, 42]. Analyzing under the fixed effects model, the overall heterogeneity $\left(\mathrm{I}_{2}=0 \%\right)$ is not significant. The overall effect is not significantly different $(\mathrm{OR}=0.90,95 \% \mathrm{Cl}=0.50-1.63)$.

Complication: intestinal obstruction (Fig. 7C).

In ten studies, 889 patients reported the incidence of postoperative intestinal obstruction[24, 25, 27, 29, 32, 36, 38-40, 42]. Analyzing under the fixed effects model, the overall heterogeneity $\left(I_{2}=0 \%\right)$ is not significant. The overall effect is not significantly different $(0 R=0.81,95 \% C l=0.38-1.70)$.

Complication: liver dysfunction (Fig. 8A).

In five studies, 426 patients reported the incidence of postoperative liver dysfunction[23, 24, 27, 29, 39]. Analyzing under the fixed effects model, the overall heterogeneity $\left(\mathrm{I}_{2}=18 \%\right)$ is not significant. The overall effect is not significantly different $(\mathrm{OR}=1.05,95 \% \mathrm{Cl}=0.49-2.24)$.

Complication: renal dysfunction (Fig. 8B).

In seven studies, 647 patients reported the incidence of postoperative renal dysfunction[23-25, 29, 36, 39, 40]. Analyzing under the fixed effects model, the overall heterogeneity $\left(\mathrm{I}_{2}=0 \%\right)$ is not significant. The occurrence of renal dysfunction after surgery was significantly favorable to the control $(\mathrm{OR}=2.44,95 \% \mathrm{Cl}=1.12-5.28)$.

Complication: pulmonary dysfunction (Fig. 8C).

In five studies, 524 patients reported the incidence of postoperative pulmonary dysfunction[24, 25, 36, 39, 40]. Analyzing under the fixed effects model, the overall heterogeneity $\left(\mathrm{I}_{2}=37 \%\right)$ is not significant. The occurrence of pulmonary dysfunction after surgery was significantly favorable to the control $(\mathrm{OR}=6.03,95 \% \mathrm{Cl}=3.08-11.80)$.

Overall complications (Fig. 8D).

In five studies, 384 patients reported the incidence of overall complications[29, 36, 40, 42, 44]. Analyzing under the fixed effects model, the overall heterogeneity $\left(\mathrm{I}_{2}=43 \%\right)$ is not significant. The overall effect is not significantly different $(\mathrm{OR}=0.95,95 \% \mathrm{Cl}=0.61-1.48)$.

Deaths due to recurrence after surgery: liver recurrence (Fig. 9A).

In two studies, 181 patients reported the deaths due to liver recurrence after surgery[34, 35]. Analyzing under the fixed effects model, the overall heterogeneity $\left(\mathrm{I}_{2}=30 \%\right)$ is not significant. The overall effect is not significantly different $(\mathrm{OR}=0.81,95 \% \mathrm{Cl}=0.28-2.31)$.

Deaths due to recurrence after surgery: lymph node and local recurrence (Fig. 9B).

In three studies, 221 patients reported the deaths due to lymph node and local recurrence after surgery[33-35]. Analyzing under the fixed effects model, the overall heterogeneity $\left(\mathrm{I}_{2}=9 \%\right)$ is not significant. The overall effect is not significantly different $(\mathrm{OR}=1.19,95 \% \mathrm{Cl}=0.54-2.62)$.

Deaths due to recurrence after surgery: peritoneum recurrence (Fig. 9C).

In four studies, 395 patients reported the deaths due to peritoneum recurrence after surgery[33-35, 37]. Analyzing under the random effects model, the overall heterogeneity $\left(\mathrm{I}_{2}=61 \%\right)$ is not significant. The overall effect is not significantly different $(\mathrm{OR}=0.37,95 \% \mathrm{Cl}=0.13-1.06)$.

Page $11 / 22$ 


\section{Discussion}

For patients at high risk of peritoneal metastasis, prophylactic HIPEC after radical gastric cancer is a method to reduce peritoneal metastasis and improve the survival rate of patients, but its effect is still controversial. Our study analyzed RCTs and high-quality NRCTs to evaluate the effect of prophylactic HIPEC on long-term survival and safety of patients. This review showed that the prophylactic HIPEC is beneficial to the overall survival rate of patients at 1,3, and 5 years, and reduces the occurrence of overall and peritoneal metastases. Our results indicate that postoperative pulmonary dysfunction and renal dysfunction are more common in the prophylactic HIPEC group. But it is regrettable that, when we evaluate deaths due to metastatic disease, HIPEC does not have enough advantages.

The overall survival rate after gastric cancer resection is a topic of concern. Many studies have reported the long-term survival rate of patients with HIPEC after surgery. Two studies reported that postoperative use of HIPEC for gastric cancer patients with peritoneal metastasis can significantly improve long-term survival[43, 45]. With the increase in the incidence of gastric cancer, the effect of prophylactic HIPEC has gradually been paid attention to. In a retrospective study, Liu et al. randomly divided 128 patients into a HIPEC group and a control group. Patients in the HIPEC group received early prophylactic HIPEC + systemic chemotherapy after gastrectomy, and the control group received chemotherapy alone[26]. Through follow-up, the 1, 2, and 5-year overall survival rates of the prophylactic HIPEC group were higher than those of the control group (P<0.05). Fujimura and his colleagues designed an RCT to evaluate the effect of prophylactic HIPEC on the overall survival rate of patients at 1, 2, and 3 years after surgery[34]. Interestingly, the author set up two experimental groups, CHPP and continuous normothermic peritoneal perfusion (CNPP), and the results reported that the overall survival rates of the two study groups were significantly different from those of the control group. A meta-analysis designed by Desidrio[46] et al. pointed out that in the subgroup of advanced gastric cancer without peritoneal metastasis, the preventive HIPEC group had 3 years $(R R=0.71,95 \% \mathrm{Cl}=0.53-0.96)$ and 5 years $(R R=0.82), 95 \% \mathrm{Cl}=0.70-0.96)$ overall survival rate is better than the control group, but there is no difference in one-year overall survival rate $(\mathrm{RR}=0.55,95 \% \mathrm{Cl}=0.23-1.30)$. Chia[47] et al. believe that this is because Desidrio and his colleagues did not evaluate tumor histology grades and chemotherapy regimens. Our study also reported the overall survival rate of patients at 1,3 , and 5 years after surgery. Consistent with our expected results, prophylactic HIPEC is beneficial to the survival rate of patients with gastric cancer after radical gastrectomy. And we evaluated the gastric cancer histology grade and HIPEC protocol included in this review. We conducted a subgroup analysis of the overall survival rate at 3-years of patients with different chemotherapy regimens after surgery, and the results affirm the role of prophylactic HIPEC in improving the survival rate of patients. Sun[48] et al.'s meta-analysis included ten RCTs and concluded that HIPEC may improve the overall survival rate of patients, but it included four low-quality studies (score $<4)$.

There are also several studies on the choice of different chemotherapeutic drugs, but due to the small number of studies and differences in doses, the evaluation results are often limited. There is no consensus on drug selection for HIPEC, MMC and platinum drugs are more common in research. The review by Gamboa[49] et al. summarized the choice of HIPEC chemotherapeutic drugs. According to reports, MMC is the first drug used for HIPEC monotherapy, and the most common regimen is $40 \mathrm{mg}$ for $90 \mathrm{~min}$. Cisplatin or oxaliplatin is usually combined with MMC. The common regimen of cisplatin is 50 to $200 \mathrm{mg} / \mathrm{m}^{2} 60-90 \mathrm{~min}$, and oxaliplatin has a fast onset, so $460 \mathrm{mg} / \mathrm{m}^{2}$ for $30-60$ minutes is common. In a PERISCOPE I initial results published in 2020, $460 \mathrm{mg} / \mathrm{m} 2$ oxaliplatin for $30 \mathrm{~min}$ with $50 \mathrm{mg} / \mathrm{m} 2$ docetaxel for $90 \mathrm{~min}$ is feasible[50]. But this way seems to be more suitable for patients with peritoneal metastases. Macri[51] et al. considered cisplatin ( $25 \mathrm{mg} / \mathrm{m}^{2}$ per liter) + MMC (3.3 mg/m² per liter) for $60 \mathrm{~min}$ may be more effective. This review conducted a subgroup analysis of three different chemotherapy methods (MMC, cisplatin, MMC+ cisplatin), and no matter which method they were, they improved the overall 3-year survival rate of patients. Due to the small number of studies and the differences in dose, duration, temperature, etc., we did not evaluate the effects between groups. In addition, prophylactic or therapeutic laparoscopic HIPEC has been mentioned in multiple studies. In the study of Badgwell[45] et al., 6 patients with positive peritoneal cytology and 14 gastric cancer patients with peritoneal metastasis used laparoscopic HIPEC as preoperative adjuvant chemotherapy. At present, there is no clear standard for the selection of HIPEC chemotherapy drugs, drug dosage, duration, etc. The publication of high-quality studies can help researchers evaluate the safety and effectiveness of different chemotherapy methods[49].

The complications of HIPEC after gastrectomy are also worrying[52]. Due to the systemic toxicity of chemotherapy drugs, patients often have complications after HIPEC. We hope that some complications are "acceptable" because they are difficult to avoid[53]. The complications of HIPEC can be divided into systemic toxicity and local toxicity. Most of the systemic toxicity is bone marrow suppression. Braam[53] et al. pointed out that this is usually related to the dose of chemotherapy drugs. Cui[28] et al. designed an RCT to evaluate postoperative myelosuppression. 48 patients were

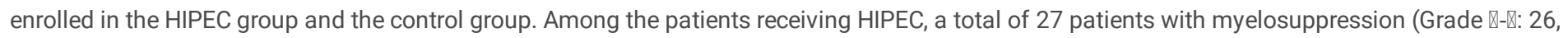

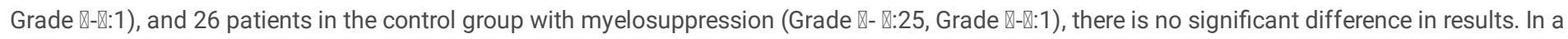
study published in 1999, none of the 141 patients in the HIPEC group and the control group had myelosuppression. Our study included 6 literatures to evaluate the occurrence of postoperative myelosuppression, and the results were also without significantly difference. HIPEC's chemotherapy drugs are directly infused into the patient's abdominal cavity, which is different from the conventional intravenous infusion of systemic chemotherapy drugs, so the effect on the whole body may not be obvious. Anastomotic leakage and postoperative intestinal obstruction are considered to be common complications of HIPEC, and the results of this review do not seem to support this view[54-56]. Like our results, the incidence of anastomotic leakage in the HIPEC group and the control group in the meta-analysis of Desiderio[46] et al. was not statistically significant ( $P=0.63)$. The study by Sun[48] et al. reported the occurrence of postoperative anastomotic leakage $(P=0.29)$ and intestinal obstruction $(P=0.77)$, and the results were also not significantly different, but the number of documents included in the analysis was small. Postoperative organ dysfunction is often reported in patients using HIPEC. In Fan[27] et al.'s study, 36 out of 50 patients developed liver dysfunction, while Zhong[24] et al. evaluated 129 patients and only 1 with

Page $12 / 22$ 
postoperative liver dysfunction. In this meta-analysis, we evaluate liver, renal, and pulmonary dysfunction after prophylactic HIPEC. The results show that prophylactic HIPEC seems to have a limited effect on liver function, and it is more likely to cause renal dysfunction and lung dysfunction. In a meta-analysis[46], the risk of renal dysfunction in the HIPEC group was significant $(P=0.01)$, which is consistent with our results. Another metaanalysis[48] that included 10 RCTs also reported that the HIPEC group had no significant effect on liver function ( $P=0.47)$. In the evaluation results of pulmonary dysfunction in this review, Kunisaki[39] et al.'s research weight is relatively large (40.6\%), and there is a certain degree of heterogeneity. In the study of Kunisaki et al., there are significant differences in postoperative pulmonary (73\% vs $19 \% ; \mathrm{P}<0.0001)$ and renal dysfunction ( $7 \%$ vs $0 \%$; $\mathrm{P}$ $<0.03)$. The toxicity of chemotherapeutics has obvious damage to renal function and lung function. Therefore, patients with organ dysfunction should be cautious in choosing HIPEC. Although our study has no statistically significant difference in the overall risk of complications $(P=0.83)$, this does not mean that the risk of certain complications can be ignored, especially organ dysfunction. HIPEC is regarded as a radical therapy by many studies, therefore, whether to use HIPEC should be discussed considering the patient's situation[19, 43, 57].

In order to reduce the occurrence of postoperative adverse events, the selection of patients before surgery should be decided through multidisciplinary consultation, and the appropriate treatment plan should be selected according to the principle of individualization[58].

The metastasis of gastric cancer has a significant impact on the survival rate of patients. This review reports the effect of prophylactic HIPEC on the overall metastasis rate and peritoneal metastasis rate, confirming that prophylactic HIPEC reduces the occurrence of gastric cancer metastasis and reduces the risk of death due to peritoneal metastasis. Koemans and his colleagues pointed out in a PERISCOPE I trial that HIPEC can improve the survival rate of patients with gastric cancer, but the control of recurrence rate is not ideal[59]. This is different from our results, which may be due to different inclusion criteria and PERISCOPE I trial. Chia[47] et al. believe that therapeutic HIPEC combined with CRS is not effective for patients with gastric cancer with peritoneal metastasis, while the effect of prophylactic HIPEC is still unclear. As an important method of perioperative chemotherapy, HIPEC is gradually recognized for its role in preventing peritoneal metastasis in advanced gastric carcinoma (AGC) patients[60]. A meta-analysis by Coccolini[61] et al. evaluated the overall metastasis rate and peritoneal metastasis rate of patients after intraperitoneal chemotherapy (IP). A total of 8 studies were included in the overall metastasis group, and 9 studies were included in the peritoneal metastasis group. Coccolini and his colleagues reported that IP improved the overall metastasis rate of patients, and prophylactic IP significantly reduced the occurrence of peritoneal metastases. This is consistent with the results of this review. An expert consensus published in 2019 pointed out that the peritoneal metastasis of some cancers should not be regarded as end-stage disease, but localized spread[51]. This suggests that the prevention of gastric cancer peritoneal metastasis should follow the principle of local treatment under the premise of systemic treatment. At the same time, the rise of immunotherapy also provides new ideas for the treatment of gastric cancer. Catumaxomab is currently in Phase III clinical trials in China, mainly for AGC patients with peritoneal metastasis. In the future, the treatment of gastric cancer will be more individualized, so the correct evaluation of patients' treatment methods will be an important part of tumor treatment[49]. Based on the existing evidence, we can basically affirm that preventive HIPEC can reduce the incidence of patients with peritoneal metastasis and the number of deaths due to peritoneal metastasis, but a large sample is still needed, and high-quality RCTs further evaluate the safety and the role of inhibiting disease progression of prophylactic HIPEC for patients.

This systematic review and meta-analysis contain some limitations. First, we included 10 NRCTs. Although they passed the quality assessment, this may affect the accuracy of the results. Second, China and Japan are two countries with a high incidence of gastric cancer, so there are more HIPECrelated clinical studies published[50]. We searched 3 Japanese literatures, but none of them were available. Two investigators searched the Chinese national knowledge infrastructure (CNKI) database, and we did not include them because the studies did not meet the inclusion criteria of this review or did not pass the quality assessment. In addition, there is a certain degree of heterogeneity in our research. For example, differences in patient characteristics, countries, medical levels, treatment plans, chemotherapy drugs, etc. may affect the credibility of the results.

\section{Conclusions}

Prophylactic HIPEC helps to improve the survival rate of gastric cancer patients after radical gastrectomy, reduces the risk of gastric cancer metastasis, and effectively prevents peritoneal metastasis. It is recommended to select suitable patients for prophylactic use of HIPEC after multidisciplinary assessment to avoid adverse events. Large samples and high-quality clinical studies are still needed to evaluate the drug selection and dosage of prophylactic HIPEC.

\section{Abbreviations}

PRISMA: Preferred Reporting Items for Systematic Reviews and Meta-analyses; HIPEC: Hyperthermic intraperitoneal chemotherapy; GC: Gastric cancer; PC: Peritoneal cancer; MINORS: Methodological index for non-randomized studies. OR: Odds ratio.

\section{Declarations}

\section{Conflict of Interest Disclosure}

This article did not receive any specific grant from funding agencies in the public, commercial, or not-for-profit sectors. 


\section{Authors' contributions}

X.H.Z. helped design the study, conduct the study, analyze the data, and write the manuscript. X.H.Z. is also the first author and is responsible for archiving the study files. Y.W.H. helped conduct the study, analyze the data, and write the manuscript. W.H.M. is corresponding author, mainly responsible for the inspection of study, and approval of the article finally.

\section{References}

1. Machlowska, J., Baj, J., Sitarz, M., Maciejewski, R. \& Sitarz, R. Gastric Cancer: Epidemiology, Risk Factors, Classification, Genomic Characteristics and Treatment Strategies.Int J Mol Sci. 2020;21.

2. Mihmanli, M., Ilhan, E., Idiz, U. O., Alemdar, A. \& Demir, U. Recent developments and innovations in gastric cancer. World J Gastroenterol, 22, 43074320 (2016).

3. Rahman, R., Asombang, A. W. \& Ibdah, J. A. Characteristics of gastric cancer in Asia. World J Gastroenterol, 20, 4483-4490 (2014).

4. Liu, X. \& Tang, M. Effect of early body cavity continuous circulation hyperthermia perfusion chemotherapy combined with systemic chemotherapy (and nursing) on survival rate and serum tumor markers in patients with advanced gastric cancer. European Journal of Inflammation, 18, 2058739220942339 (2020).

5. Swan, R. \& Miner, T. J. Current role of surgical therapy in gastric cancer. World J Gastroenterol, 12, 372-379 (2006).

6. Thomassen, I. et al. Peritoneal carcinomatosis of gastric origin: a population-based study on incidence, survival and risk factors. Int $J$ Cancer, 134 , 622-628 (2014).

7. Sakuramoto, S. et al. Adjuvant chemotherapy for gastric cancer with S-1, an oral fluoropyrimidine. N Engl J Med, 357, 1810-1820 (2007).

8. Cunningham, D. et al. Perioperative chemotherapy versus surgery alone for resectable gastroesophageal cancer. N Engl J Med, 355, 11-20 (2006).

9. Flessner, M. F. The transport barrier in intraperitoneal therapy. Am J Physiol Renal Physiol, 288, F433-42 (2005).

10. Jacquet, P. \& Sugarbaker, P. H. Peritoneal-plasma barrier. Cancer Treat Res, 82, 53-63 (1996).

11. Dedrick, R. L., Myers, C. E., Bungay, P. M. \& DeVita, V. T. Jr. Pharmacokinetic rationale for peritoneal drug administration in the treatment of ovarian cancer. Cancer Treat Rep, 62, 1-11 (1978).

12. Seynhaeve, A. L. B., Amin, M., Haemmerich, D., van Rhoon, G. C. \& Ten Hagen, T. L. M. Hyperthermia and smart drug delivery systems for solid tumor therapy. Adv Drug Deliv Rev, 163-164, 125-144 (2020).

13. Hehr, T., Wust, P., Bamberg, M. \& Budach, W. Current and potential role of thermoradiotherapy for solid tumours. Onkologie, 26, 295-302 (2003).

14. Seshadri, R. A. \& Glehen, O. Cytoreductive surgery and hyperthermic intraperitoneal chemotherapy in gastric cancer. World J Gastroenterol, 22, 1114-1130 (2016).

15. Yan, T. D. et al. A systematic review and meta-analysis of the randomized controlled trials on adjuvant intraperitoneal chemotherapy for resectable gastric cancer. Ann Surg Oncol, 14, 2702-2713 (2007).

16. Slim, K. et al. Methodological index for non-randomized studies (minors): development and validation of a new instrument. ANZ J Surg, 73, 712716 (2003).

17. Vinuela, E. F., Gonen, M., Brennan, M. F., Coit, D. G. \& Strong, V. E. Laparoscopic versus open distal gastrectomy for gastric cancer: a meta-analysis of randomized controlled trials and high-quality nonrandomized studies. Ann Surg, 255, 446-456 (2012).

18. Gao, L-Z. et al. Hyperthermic intraperitoneal chemotherapy plus high-frequency diathermic therapy followed by intravenous chemotherapy versus intravenous chemotherapy alone for postoperative adjuvant treatment of gastrointestinal cancer: a comparative research study. Journal of Buon, 21, 1510-1517 (2016).

19. Hall, J. J. et al. Cytoreductive surgery with intraperitoneal hyperthermic chemotherapy for advanced gastric cancer. Journal of gastrointestinal surgery: official journal of the Society for Surgery of the Alimentary Tract, 8, 454-463 (2004).

20. Zhang, H. W. et al. Postoperative intraperitoneal hyperthermic perfusion improve survival for advanced gastric cancer.Medicine (United States). 2019;98.

21. Akiyama, H. et al. [Effectiveness of continuous hyperthermic peritoneal perfusion for the peritoneal dissemination of gastric cancer]. Gan To Kagaku Ryoho, 29, 2168-2173 (2002).

22. Kobayashi, K., Fujimoto, S., Takahashi, M., Muto, T. \& Toyosawa, T. [Clinical result of intraperitoneal hyperthermic chemoperfusion for gastric cancer with serosal invasion to prevent peritoneal recurrence]. Gan To Kagaku Ryoho, 25, 1436-1438 (1998).

23. Zhu, L. et al. Prophylactic chemotherapeutic hyperthermic intraperitoneal perfusion reduces peritoneal metastasis in gastric cancer: A retrospective clinical study.BMC Cancer. 2020;20.

24. Zhong, Y. et al. Lobaplatin in prophylactic hyperthermic intraperitoneal chemotherapy for advanced gastric cancer: Safety and efficacy profiles. Cancer Management and Research, 12, 5141-5146 (2020).

25. Xie, T. Y. et al. Role of prophylactic hyperthermic intraperitoneal chemotherapy in patients with locally advanced gastric cancer. World journal of gastrointestinal oncology, 12, 782-790 (2020). 
26. Liu, X. \& Tang, M. Effect of early body cavity continuous circulation hyperthermia perfusion chemotherapy combined with systemic chemotherapy (and nursing) on survival rate and serum tumor markers in patients with advanced gastric cancer.European journal of inflammation. $2020 ; 18$.

27. Fan, B. et al. Phase II trial of prophylactic hyperthermic intraperitoneal chemotherapy in patients with locally advanced gastric cancer after curative surgery. BMC cancer, 21, 216 (2021).

28. Cui, H. B. et al. Effect of neoadjuvant chemotherapy combined with hyperthermic intraperitoneal perfusion chemotherapy on advanced gastric cancer. Experimental and therapeutic medicine, 7, 1083-1088 (2014).

29. Beeharry, M. K. et al. Prophylactic HIPEC with radical D2 gastrectomy improves survival and peritoneal recurrence rates for locally advanced gastric cancer: personal experience from a randomized case control study. BMC Cancer, 19, 932 (2019).

30. Kang, L. Y. et al. Intraoperative hyperthermic intraperitoneal chemotherapy as adjuvant chemotherapy for advanced gastric cancer patients with serosal invasion. J Chin Med Assoc, 76, 425-431 (2013).

31. Yonemura, Y. et al. Prophylaxis with intraoperative chemohyperthermia against peritoneal recurrence of serosal invasion-positive gastric cancer. World Journal of Surgery, 19, 450-455 (1995).

32. Koga, S. et al. Prophylactic therapy for peritoneal recurrence of gastric cancer by continuous hyperthermic peritoneal perfusion with mitomycin C., 61, 232-237 (1988).

33. Hamazoe, R., Maeta, M. \& Kaibara, N. Intraperitoneal thermochemotherapy for prevention of peritoneal recurrence of gastric cancer. Final results of a randomized controlled study., 73, 2048-2052 (1994).

34. Fujimura, T. et al. Continuous hyperthermic peritoneal perfusion for the prevention of peritoneal recurrence of gastric cancer: randomized controlled study. World journal of surgery, 18, 150-155 (1994).

35. Fujimoto, S., Takahashi, M., Mutou, T., Kobayashi, K. \& Toyosawa, T. Successful intraperitoneal hyperthermic chemoperfusion for the prevention of postoperative peritoneal recurrence in patients with advanced gastric carcinoma., 85, 529-534 (1999).

36. Hirose, K. et al. Efficacy of continuous hyperthermic peritoneal perfusion for the prophylaxis and treatment of peritoneal metastasis of advanced gastric cancer: evaluation by multivariate regression analysis. Oncology, 57, 106-114 (1999).

37. Ikeguchi, M. et al. Effects of continuous hyperthermic peritoneal perfusion on prognosis of gastric cancer with serosal invasion. Eur J Surg, 161, 581-586 (1995).

38. Takahashi, T., Hagiwara, A., Shimotsuma, M., Sawai, K. \& Yamaguchi, T. Prophylaxis and treatment of peritoneal carcinomatosis: intraperitoneal chemotherapy with mitomycin C bound to activated carbon particles. World J Surg, 19, 565-569 (1995).

39. Kunisaki, C. et al. Lack of efficacy of prophylactic continuous hyperthermic peritoneal perfusion on subsequent peritoneal recurrence and survival in patients with advanced gastric cancer. Surgery, 131, 521-528 (2002).

40. Kim, J. Y. \& Bae, H. S. A controlled clinical study of serosa-invasive gastric carcinoma patients who underwent surgery plus intraperitoneal hyperthermo-chemo-perfusion (IHCP)., 4, 27-33 (2001).

41. Reutovich, M. Y., Krasko, O. V. \& Sukonko, O. G. Hyperthermic intraperitoneal chemotherapy in serosa-invasive gastric cancer patients. European journal of surgical oncology, 45, 2405-2411 (2019).

42. Rosa, F. et al. Survival advantage of cytoreductive surgery and hyperthermic intraperitoneal chemotherapy (HIPEC) for advanced gastric cancer: experience from a Western tertiary referral center (Langenbeck's archives of surgery, 2021).

43. Yarema, R. R. et al. Hyperthermic intraperitoneal chemoperfusion in combined treatment of locally advanced and disseminated gastric cancer: results of a single-centre retrospective study. Int J Hyperthermia, 30, 159-165 (2014).

44. Diniz, T. P. et al. Fonseca, „, Does hipec improve outcomes in gastric cancer patients treated with perioperative chemotherapy and radical surgery? A propensity-score matched analysis. Journal of Surgical Oncology. 2020;121:823-32.

45. Badgwell, B. et al. A Phase II Trial of Cytoreduction, Gastrectomy, and Hyperthermic Intraperitoneal Perfusion with Chemotherapy for Patients with Gastric Cancer and Carcinomatosis or Positive Cytology. Ann Surg Oncol, 28, 258-264 (2021).

46. Desiderio, J. et al. The 30-year experience-A meta-analysis of randomised and high-quality non-randomised studies of hyperthermic intraperitoneal chemotherapy in the treatment of gastric cancer. European Journal of Cancer, 79, 1-14 (2017).

47. Chia, D. K. A. \& So, J. B. Y. Recent Advances in Intra-peritoneal Chemotherapy for Gastric Cancer. J Gastric Cancer, 20, 115-126 (2020).

48. Sun, J. et al. Benefits of hyperthermic intraperitoneal chemotherapy for patients with serosal invasion in gastric cancer: a meta-analysis of the randomized controlled trials. BMC Cancer, 12, 526 (2012).

49. Gamboa, A. C. \& Winer, J. H. Cytoreductive Surgery and Hyperthermic Intraperitoneal Chemotherapy for Gastric Cancer.Cancers (Basel). $2019 ; 11$.

50. van der Kaaij, R. T. et al. Treatment of PERItoneal disease in Stomach Cancer with cytOreductive surgery and hyperthermic intraPEritoneal chemotherapy: PERISCOPE I initial results. Br J Surg, 107, 1520-1528 (2020).

51. Macri, A. \& Morabito, F. The use of intraperitoneal chemotherapy for gastric malignancies. Expert Rev Anticancer Ther, 19, 879-888 (2019).

52. Blum Murphy, M. et al. Phase I Trial of Hyperthermic Intraperitoneal Chemoperfusion (HIPEC) with Cisplatin, Mitomycin, and Paclitaxel in Patients with Gastric Adenocarcinoma and Associated Carcinomatosis or Positive Cytology. Ann Surg Oncol, 27, 2806-2811 (2020).

53. Braam, H. J. et al. Selection of chemotherapy for hyperthermic intraperitoneal use in gastric cancer. Crit Rev Oncol Hematol, 95, 282-296 (2015).

54. Montori, G. et al. The treatment of peritoneal carcinomatosis in advanced gastric cancer: state of the art. Int J Surg Oncol, 2014, 912418 (2014).

Page 15/22 
55. Gill, R. S. et al. Treatment of gastric cancer with peritoneal carcinomatosis by cytoreductive surgery and HIPEC: a systematic review of survival, mortality, and morbidity. J Surg Oncol, 104, 692-698 (2011).

56. Roviello, F. et al. Treatment of peritoneal carcinomatosis with cytoreductive surgery and hyperthermic intraperitoneal chemotherapy: state of the art and future developments. Surg Oncol, 20, e38-54 (2011).

57. Yang, X. J. et al. Cytoreductive surgery and hyperthermic intraperitoneal chemotherapy improves survival of patients with peritoneal carcinomatosis from gastric cancer: final results of a phase III randomized clinical trial. Ann Surg Oncol, 18, 1575-1581 (2011).

58. Rudloff, U. et al. Impact of maximal cytoreductive surgery plus regional heated intraperitoneal chemotherapy (HIPEC) on outcome of patients with peritoneal carcinomatosis of gastric origin: results of the GYMSSA trial. J Surg Oncol, 110, 275-284 (2014).

59. Koemans, W. J. et al. Tumor characteristics and clinical outcome of peritoneal metastasis of gastric origin treated with a hyperthermic intraperitoneal chemotherapy procedure in the PERISCOPE I trial. J Surg Oncol, 123, 904-910 (2021).

60. Beeharry, M. K., Zhang, T. Q., Liu, W. T. \& Gang, Z. Z. Optimization of perioperative approaches for advanced and late stages of gastric cancer: clinical proposal based on literature evidence, personal experience, and ongoing trials and research. World J Surg Oncol, 18, 51 (2020).

61. Coccolini, F. et al. Intraperitoneal chemotherapy in advanced gastric cancer. Meta-analysis of randomized trials. Eur J Surg Oncol, 40, 12-26 (2014).

\section{Figures}

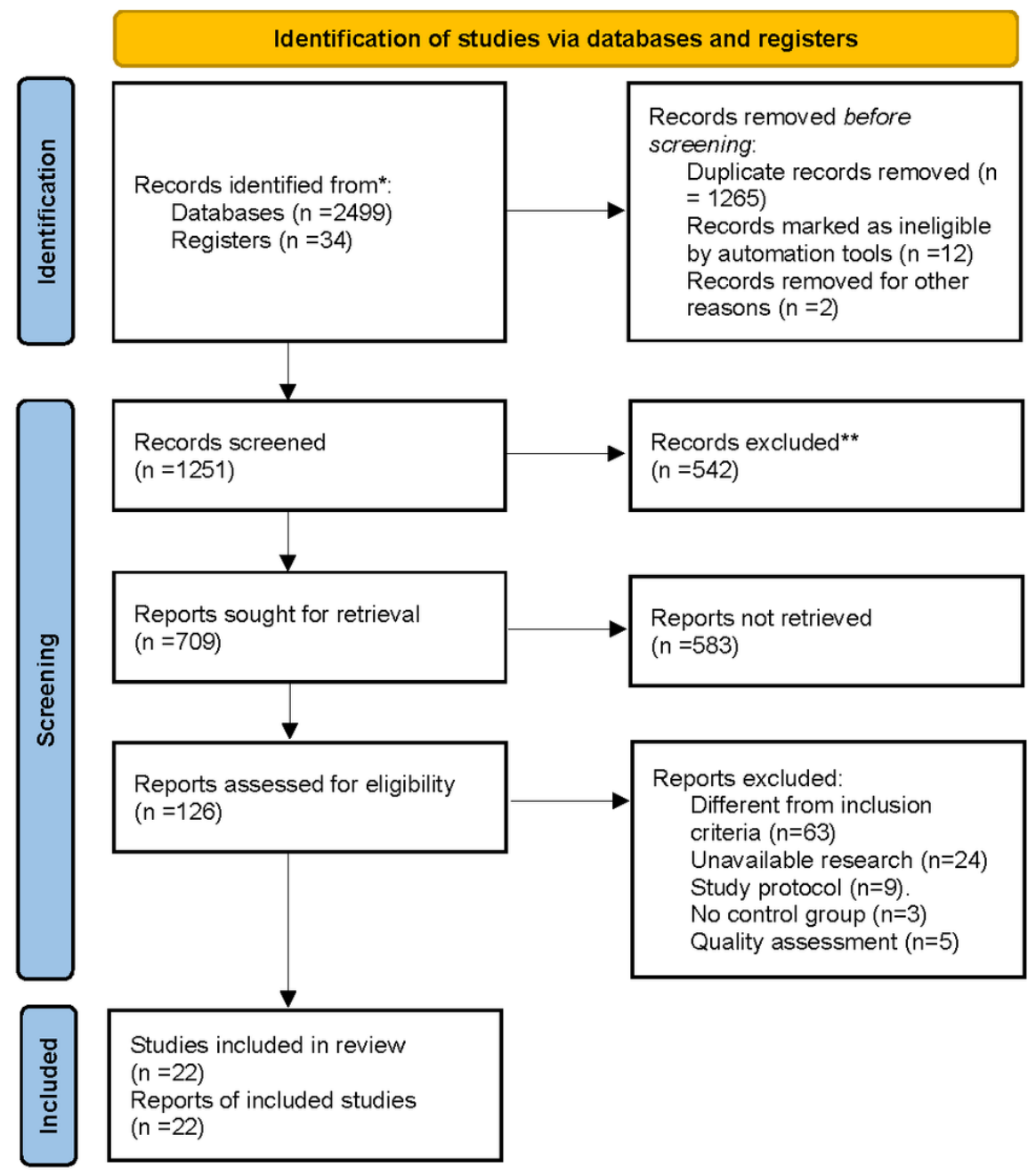

Figure 1

PRISMA Flow diagram of search strategy and included studies. 


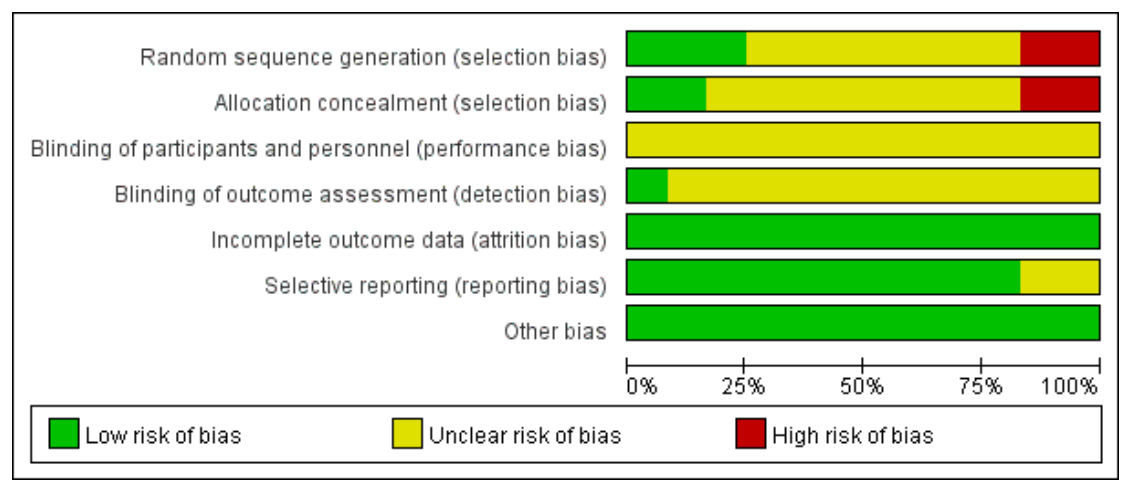

Figure 2

Risk of bias graph: review authors' judgements about each risk of bias item presented as percentages across all included studies.

\begin{tabular}{|c|c|c|c|c|c|c|c|}
\hline & 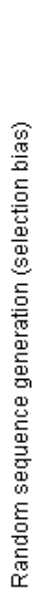 & 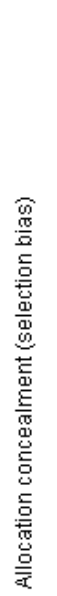 & 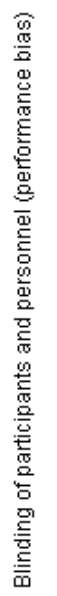 & 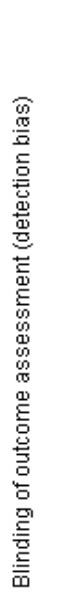 & 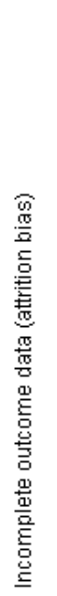 & 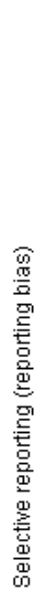 & 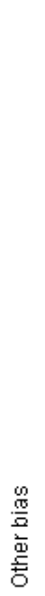 \\
\hline Beeharry 2019 & $\odot$ & $\odot$ & $?$ & + & + & $\odot$ & $\odot$ \\
\hline Cui 2014 & $?$ & $?$ & $?$ & $?$ & $\odot$ & $\odot$ & $\odot$ \\
\hline Fan 2021 & $\odot$ & $?$ & $?$ & $?$ & 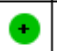 & $\odot$ & $\odot$ \\
\hline Fujimoto 1999 & $?$ & $?$ & $?$ & $?$ & $\oplus$ & $\odot$ & $\odot$ \\
\hline Fujimura 1994 & $?$ & $?$ & $?$ & $?$ & 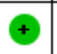 & $\odot$ & $\odot$ \\
\hline Hamazoe 1994 & $?$ & $?$ & $?$ & $?$ & 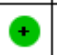 & $\odot$ & $\oplus$ \\
\hline Hirose 1999 & O & ○ & $?$ & $?$ & 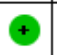 & $?$ & $\odot$ \\
\hline Ikeguchi 1995 & $?$ & $?$ & $?$ & $?$ & 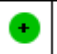 & $\odot$ & $\odot$ \\
\hline Kim 2001 & ○ & ○ & $?$ & $?$ & $\oplus$ & + & + \\
\hline Koga 1988 & $?$ & $?$ & $?$ & $?$ & 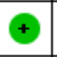 & $?$ & + \\
\hline Reutovich 2019 & $?$ & $?$ & $?$ & $?$ & $\oplus$ & $\odot$ & $\odot$ \\
\hline Takahashi 1995 & $\odot$ & $\odot$ & $?$ & $?$ & $\odot$ & $\odot$ & $\odot$ \\
\hline
\end{tabular}

\section{Figure 3}

Risk of bias summary: review authors' judgements about each risk of bias item for each included study. 


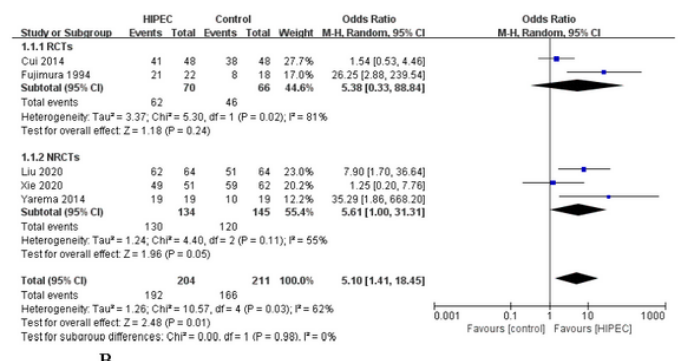

B
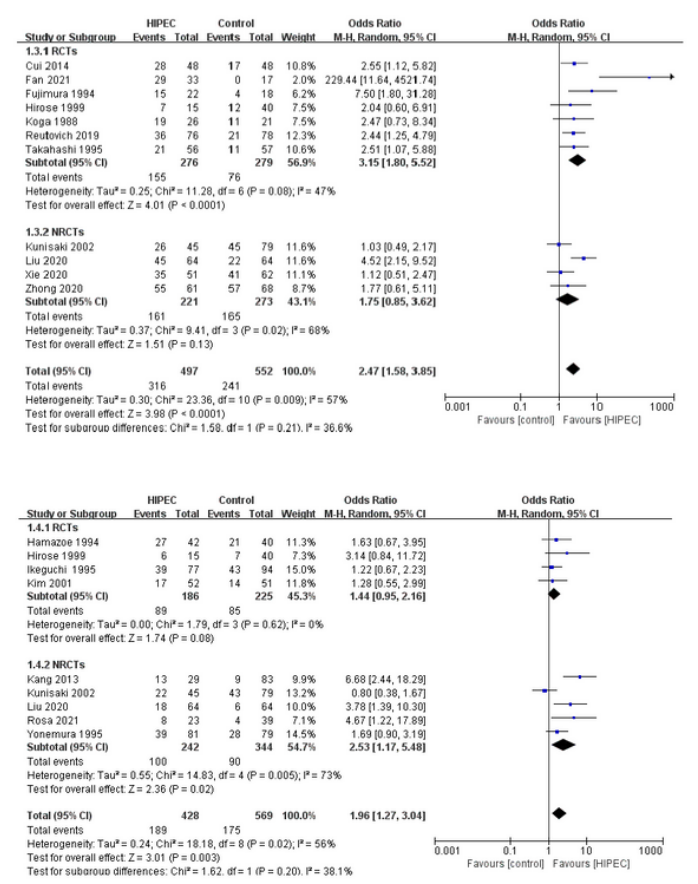

Figure 4

Overall 1-year survival (A), Overall 3-year survival (B). Overall 5-year survival. 
HIPEC Control Odds Ratio $\quad$ Odds Ratio

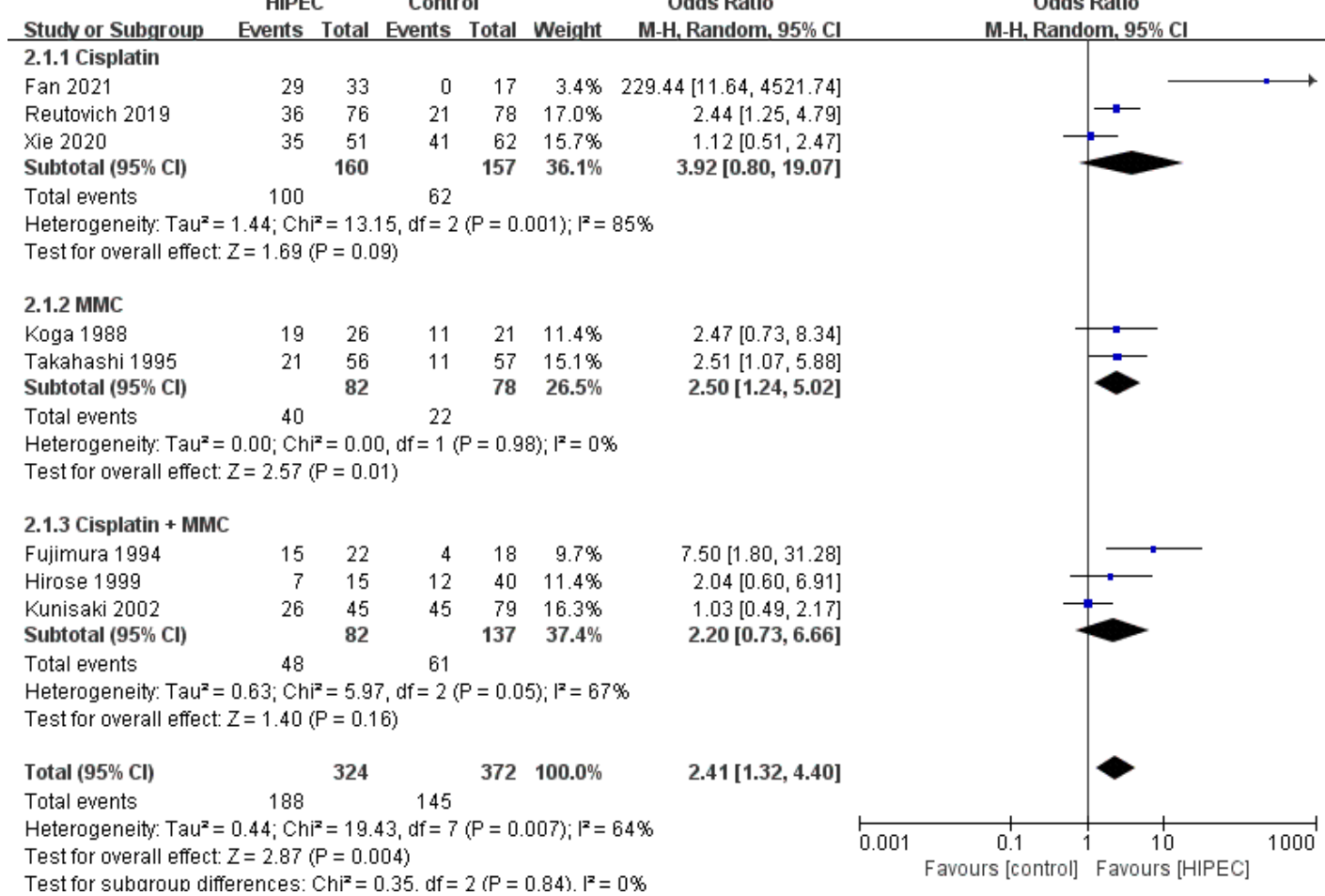

\section{Figure 5}

Overall 3-year survival in different HIPEC ways.

\section{A}

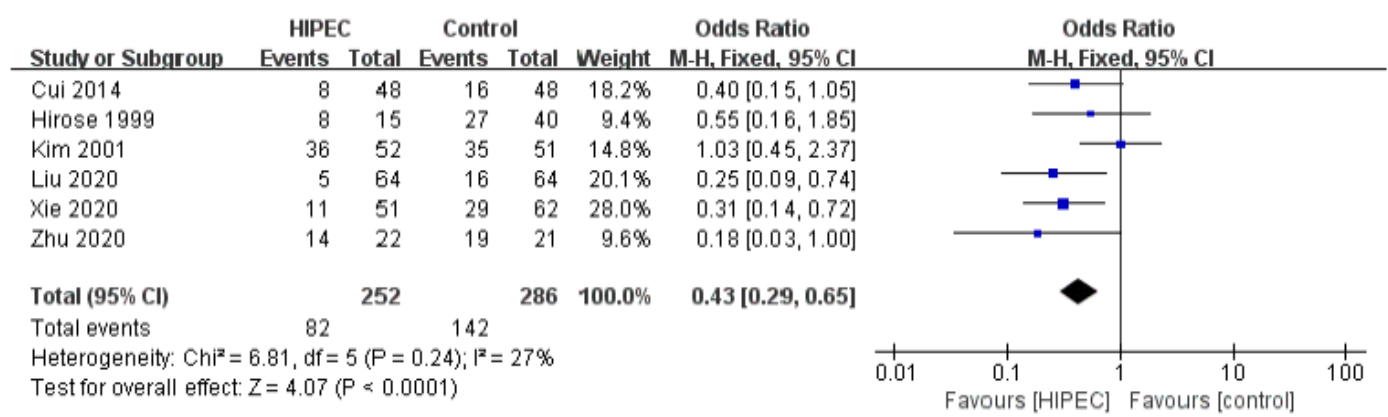

\section{B}

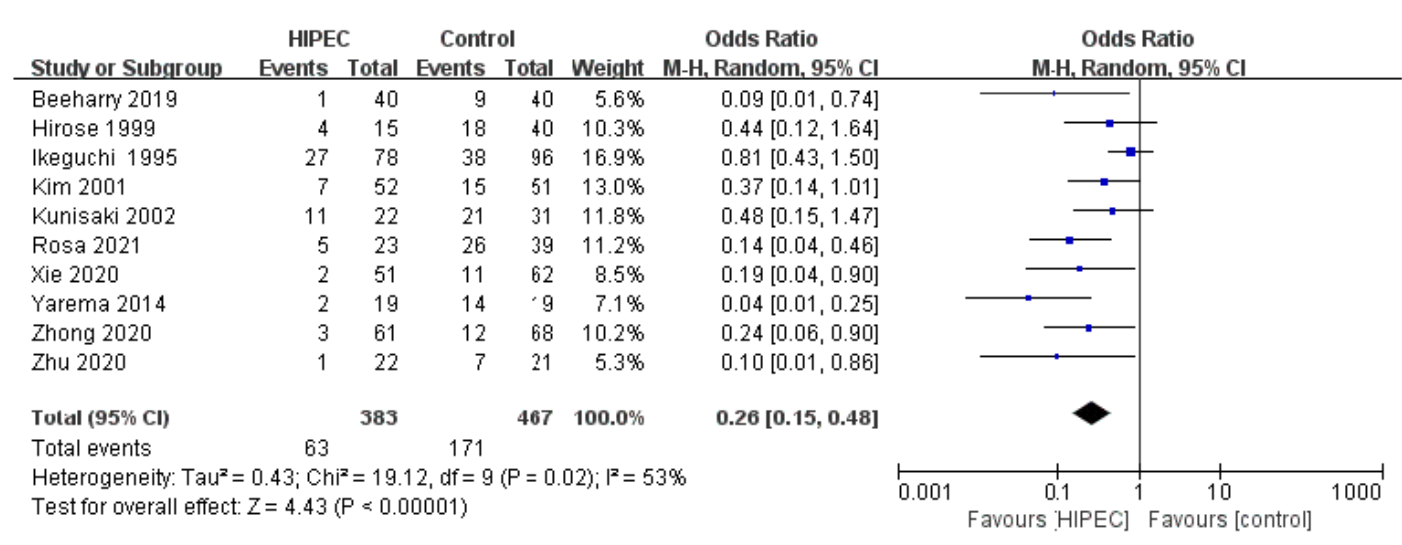

Figure 6

Overall recurrence rate $(A)$, Peritoneal recurrence rate $(B)$. 
A

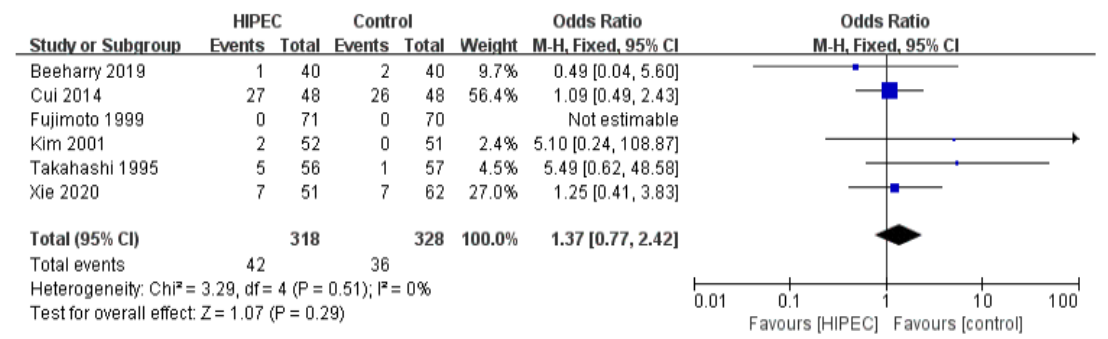

B

\begin{tabular}{|c|c|c|c|c|c|c|c|c|c|c|}
\hline Studv or Subgroup & $\begin{array}{l}\text { HIPEC } \\
\text { Events }\end{array}$ & Total & $\begin{array}{l}\text { Contro } \\
\text { Events }\end{array}$ & $\begin{array}{l}\text { ol } \\
\text { Total }\end{array}$ & Weight & $\begin{array}{l}\text { Odds Ratio } \\
\text { M-H, Fixed, } 95 \% \mathrm{Cl}\end{array}$ & & $\begin{array}{r}\text { Odds } \\
\text { M-H, Fixes }\end{array}$ & $\begin{array}{l}\text { Ratio } \\
\text { ed, } 95 \% \mathrm{Cl}\end{array}$ & \\
\hline Beeharry 2019 & 0 & 40 & 1 & 40 & $6.4 \%$ & $0.33[0.01,8.22]$ & & & & \\
\hline F an 2021 & 4 & 29 & 1 & 16 & $4.8 \%$ & $2.40[0.24,23.53]$ & & & & \\
\hline Fujimoto 1999 & 2 & 71 & 2 & 70 & $8.5 \%$ & $0.99[0.13,7.20]$ & & & & \\
\hline Hamazoe 1994 & 2 & 42 & 3 & 40 & $12.7 \%$ & $0.62[0.10,3.90]$ & & $\rightarrow$ & & \\
\hline Hirose 1999 & 3 & 15 & 6 & 40 & $11.4 \%$ & $1.42[0.31,6.57]$ & & & & \\
\hline Kim 2001 & 1 & 52 & 2 & 51 & $8.6 \%$ & $0.48[0.04,5.47]$ & & & & \\
\hline Koga 1988 & 1 & 32 & 2 & 28 & $9.0 \%$ & $0.42[0.04,4.89]$ & & & & \\
\hline Kunisaki 2002 & 1 & 45 & 2 & 79 & $6.2 \%$ & $0.88[0.08,9.93]$ & & & & \\
\hline Rosa 2021 & 1 & 23 & 4 & 39 & $12.4 \%$ & $0.40[0.04,3.79]$ & & & & \\
\hline Takahashi 1995 & 3 & 56 & 2 & 57 & $8.2 \%$ & $1.56[0.25,9.69]$ & & & & \\
\hline Xie 2020 & 0 & 51 & 0 & 62 & & Not estimable & & & & \\
\hline Zhong 2020 & 3 & 61 & 3 & 68 & $11.7 \%$ & $1.12[0.22,5.77]$ & & & & \\
\hline Total $(95 \% \mathrm{Cl})$ & & 517 & & 590 & $100.0 \%$ & $0.90[0.50,1.63]$ & & & & \\
\hline Total events & 21 & & 28 & & & & & & & \\
\hline $\begin{array}{l}\text { Heterogeneity: } \mathrm{Chi}^{2}= \\
\text { Test for overall effect }\end{array}$ & $\begin{array}{l}\text { 3.14, df }= \\
Z=0.34(\end{array}$ & $\begin{array}{l}10(P= \\
P=0.73\end{array}$ & $0.98) ; I^{2}=$ & $=0 \%$ & & & 0.001 & $\begin{array}{cc}0.1 & 1 \\
\text { avours [HIPEC] }\end{array}$ & $\begin{array}{cc}1 & 10 \\
\text { Favours [control] }\end{array}$ & 1000 \\
\hline
\end{tabular}

$\mathrm{C}$

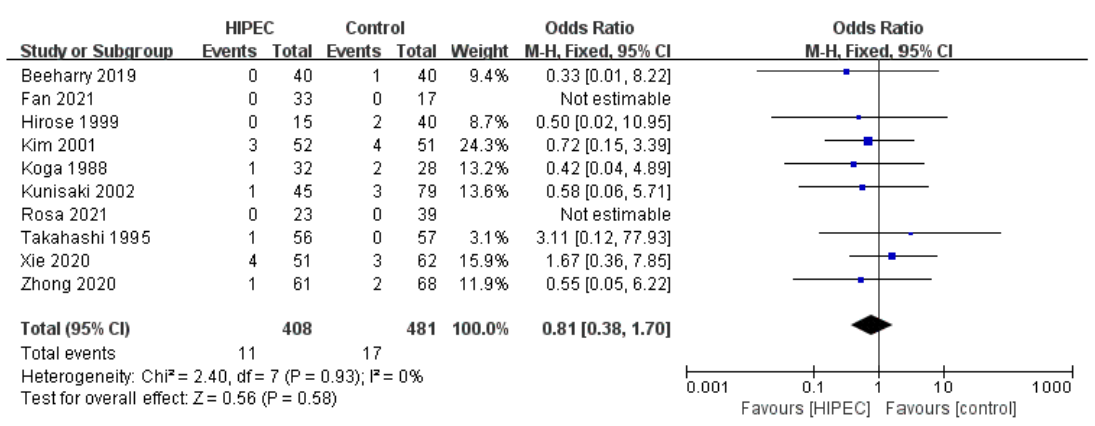

Figure 7

Complication: myelosuppression (A), Complication: leakage (B), Complication: intestinal obstruction (C). 
A

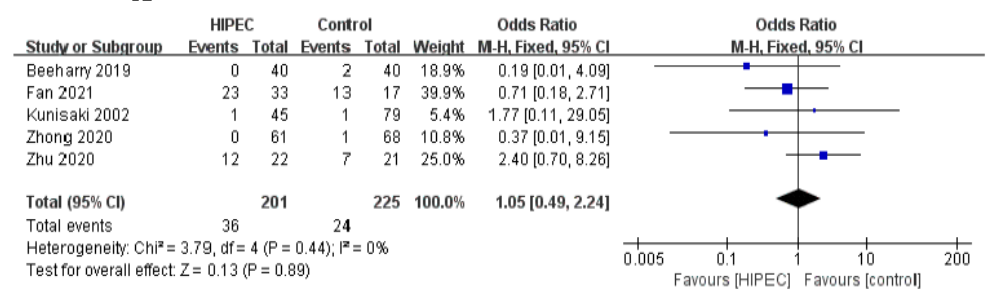

B

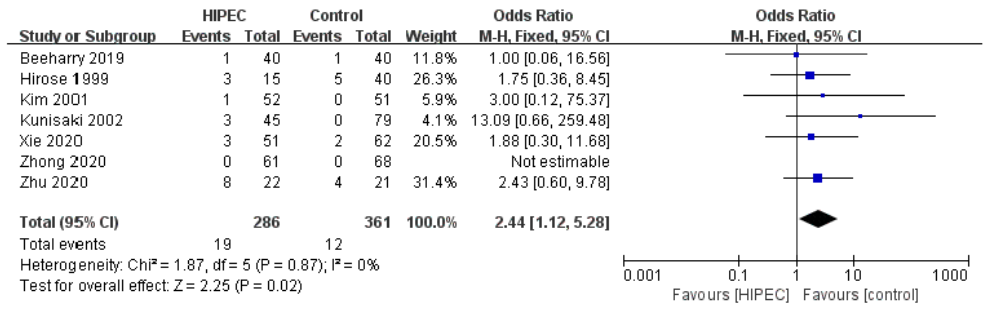

C

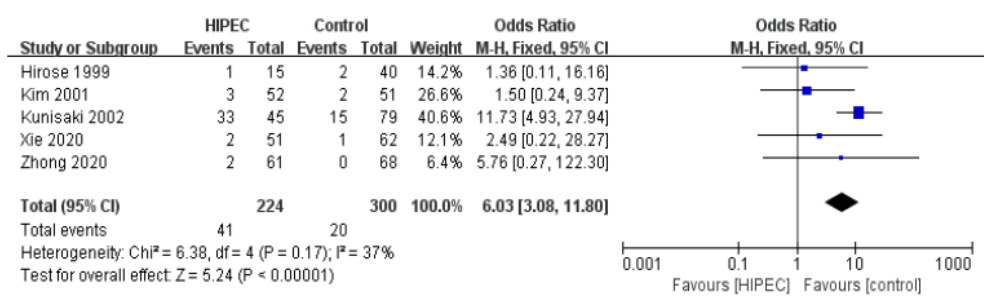

D

\begin{tabular}{|c|c|c|c|c|c|c|c|c|c|c|}
\hline Studv or Subgroup & $\begin{array}{l}\text { HIIPEC } \\
\text { Events }\end{array}$ & & $\begin{array}{l}\text { Contro } \\
\text { Events }\end{array}$ & & Weight & $\begin{array}{l}\text { Odds Ratio } \\
\text { M-H. Fixed, } 95 \% \mathrm{Cl}\end{array}$ & & $\begin{array}{r}\text { Odds } \\
\text { M-H. Fixe }\end{array}$ & $\begin{array}{l}\text { Ratio } \\
\text { d, } 95 \% \mathrm{Cl}\end{array}$ & \\
\hline Beeharry 2019 & 3 & 40 & 11 & 40 & $25.1 \%$ & $0.21[0.05,0.84]$ & & 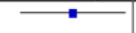 & & \\
\hline Diniz 2020 & 12 & 28 & 20 & 56 & $18.8 \%$ & $1.35[0.53,3.41]$ & & - & - & \\
\hline Hirose 1999 & 9 & 15 & 17 & 40 & $9.2 \%$ & $2.03[0.61,6.79]$ & & & & \\
\hline Kim 2001 & 19 & 52 & 17 & 51 & $26.9 \%$ & $1.15[0.51,2.59]$ & & 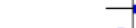 & & \\
\hline Rosa 2021 & 9 & 23 & 18 & 39 & $20.1 \%$ & $0.75[0.26,2.14]$ & & & - & \\
\hline Total (95\% Cl) & & 158 & & 226 & $100.0 \%$ & $0.95[0.61,1.48]$ & & & & \\
\hline Total events & 52 & & 83 & & & & & & & \\
\hline $\begin{array}{l}\text { Heterogeneity: } \mathrm{Ch}^{2}= \\
\text { Test for overall effect }\end{array}$ & $\begin{array}{l}7.06, d f= \\
Z=0.21(P\end{array}$ & $\begin{array}{l}4(P=0 \\
=0.83\end{array}$ & 3) & $=43 \%$ & & & 0.01 & $\begin{array}{c}0.1 \\
\text { Favours [HIPEC] }\end{array}$ & Favours | & $\begin{array}{ll}10 & 100 \\
\text { [control] } & \end{array}$ \\
\hline
\end{tabular}

\section{Figure 8}

Complication: liver dysfunction (A), Complication: renal dysfunction (B), Complication: pulmonary dysfunction (C), Overall complication (D). 
A

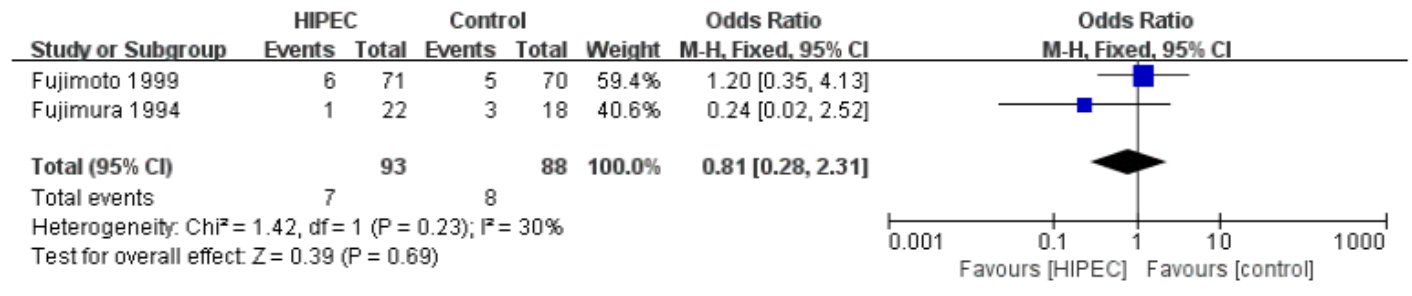

B

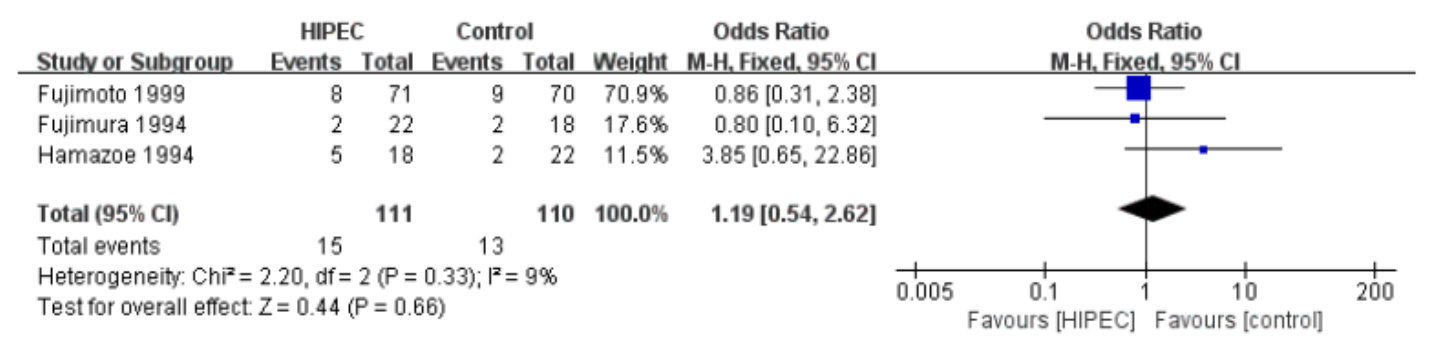

C

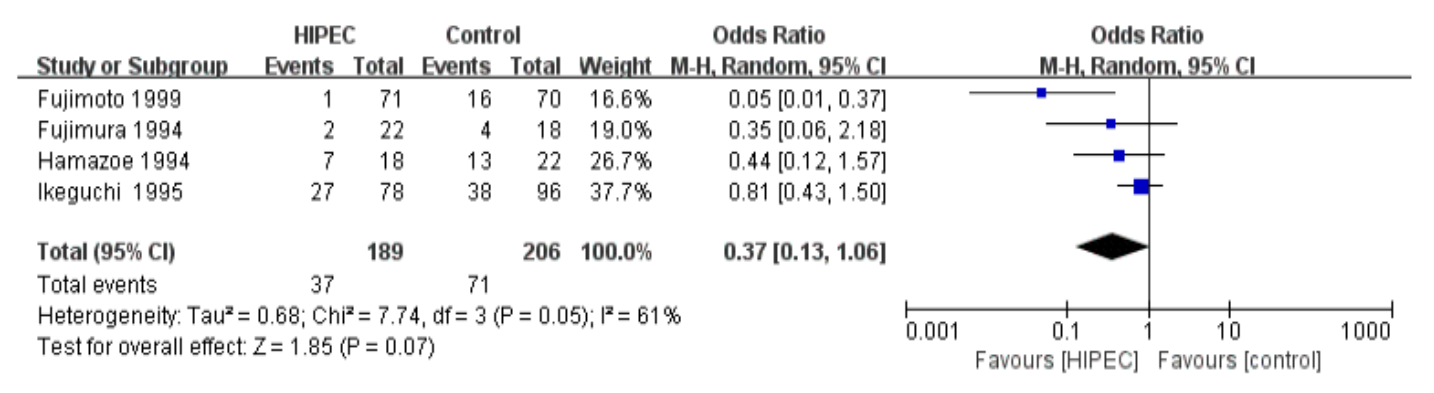

Figure 9

Death due to recurrence after surgery: liver recurrence (A), Death due to recurrence after surgery: lymph node and local recurrence (B), Death due to recurrence after surgery: peritoneum recurrence (C). 